\title{
Nanostructured $\mathrm{RuO}_{2}$ on MWCNTs: Efficient catalyst for transfer hydrogenation of carbonyl compounds and aerial oxidation of alcohols
}

M. Gopiraman ${ }^{\mathrm{a}}$, S. Ganesh Babu, ${ }^{\mathrm{a}, \mathrm{b}}$, R. Karvembu ${ }^{\mathrm{c}, *}, \mathrm{I} . \mathrm{S} . \mathrm{Kim}^{\mathrm{a}, \mathrm{d} *}$

${ }^{a}$ Nano Fusion Technology Research Lab, Interdisciplinary Graduate School of Science and Technology, National University Corporation, Shinshu University, Ueda, Nagano 386 8567, Japan

${ }^{b}$ SRM Research Institute, SRM University, Kattankulathur 603203, India

${ }^{c}$ Department of Chemistry, National Institute of Technology, Tiruchirappalli 620 015, India

${ }^{d}$ Interdisciplinary Cluster for Cutting Edge Research (ICCER), Division of Frontier Fibers, Institute for Fiber Engineering (IFES), Shinshu University, Ueda, Nagano 386 8567, Japan

\footnotetext{
a,* Corresponding author. Tel.: +8126821 5139; fax: +81268215482.

E-mail address: kim@shinshu-u.ac.jp (I.S. Kim).

b,* Corresponding author. Tel.: + 91431 2503636; fax: +91 4312500133 .

E-mail address: kar@nitt.edu (R. Karvembu).
} 


\section{ABSTRACT}

Multiwall carbon nanotubes (MWCNTs)/ruthenium dioxide nanoparticles $\left(\mathrm{RuO}_{2} \mathrm{NPs}\right)$ composite was prepared by a straightforward 'dry synthesis' method. After being well characterized, the prepared composite was used as a nanocatalyst $\left(\mathrm{RuO}_{2} / \mathrm{MWCNT}\right)$ for the transfer hydrogenation of carbonyl compounds. The excellent adhesion of $\mathrm{RuO}_{2} \mathrm{NPs}$ on the anchoring sites of MWCNTs was confirmed by TEM and Raman analyses. The weight percentage $(7.97 \mathrm{wt} \%)$ and the chemical state (+4) of $\mathrm{Ru}$ in $\mathrm{RuO}_{2} / \mathrm{MWCNT}$ was confirmed by EDS and XPS analyses, respectively. It was found that the $\mathrm{RuO}_{2} / \mathrm{MWCNT}$ has a higher specific surface area of $189.3 \mathrm{~m}^{2}$ $\mathrm{g}^{-1}$. Initially the reaction conditions were optimized and then the scope of the catalytic system was extended with a wide range of carbonyl compounds. The influence of the size of $\mathrm{RuO}_{2} \mathrm{NPs}$ on the transfer hydrogenation of carbonyl compounds was also studied. The $\mathrm{RuO}_{2} / \mathrm{MWCNT}$ is highly chemoselective, heterogeneous in nature, reusable and highly stable. Owing to the high stability of the used catalyst $\left(u-\mathrm{RuO}_{2} / \mathrm{MWCNT}\right)$, it was further calcinated at high temperature to obtain $\mathrm{RuO}_{2}$ nanorods (NRs) hybrid MWCNTs. Then the hybrid material was used as a catalyst $\left(r-\mathrm{RuO}_{2} / \mathrm{MWCNT}\right)$ for the aerial oxidation of alcohols and the result was found to be good.

Keywords: MWCNTs, $\mathrm{RuO}_{2}$ nanostructures, Dry synthesis, Heterogeneous catalyst, Transfer hydrogenation, Aerial oxidation 


\section{Introduction}

Catalytic reduction of carbonyl compounds $(\mathrm{C}=\mathrm{O})$ to their corresponding alcohols is an essential organic transformation in both industrial and fine chemical processes $[1,2]$. There are several metal-based catalytic systems have long been proposed to perform this transformation [3, 4]. However, due to simple and cost effective protocol, most of the recent studies are focused on the transition metal-catalyzed transfer hydrogenation of carbonyl compounds by using 2propanol $(i-\mathrm{PrOH})$ as a hydrogen donor [5]. From an economical point of view, heterogeneous metal nanoparticles (MNPs) including ruthenium nanoparticles (RuNPs) have advantages over homogeneous catalysts due to their simple recovery and reusability [6, 7]. Particularly, RuNPssupported catalysts have been widely employed for the reduction of carbonyl compounds due to their high activity, selectivity, versatility and reusability [8-10]. Kantam et al., [11] investigated $\mathrm{MgO}$ stabilized RuNPs catalyst for the transfer hydrogenation of carbonyl compounds. Yamaguchi et al., [12] prepared highly dispersed $\mathrm{Ru}(\mathrm{OH})_{\mathrm{x}} / \mathrm{TiO}_{2}$ composite and used as a catalyst for the liquid-phase hydrogen transfer reactions. They found that the $\mathrm{Ru}(\mathrm{OH})_{\mathrm{x}} / \mathrm{TiO}_{2}$ catalyst is highly effective and selective. In spite of higher catalytic activity, most of the common RuNPs (supported on metal oxide and polymeric materials) often exhibit less stability in high basic and acidic reaction conditions and, consequently, the reusability and selectivity of the catalyst are highly limited [13]. Therefore, developing an efficient and stable catalyst for the transfer hydrogenation of carbonyl compounds is still a challenging task.

Among the carbon building blocks (CNTs, fullerenes, graphene and carbon nanofibers), multiwall carbon nanotubes (MWCNTs) have played a significant role as a support in various fields including catalysis $[14,15]$. In fact, MWCNTs have unique and superior properties such as chemical inertness, high stability and huge surface area [16]. Till date, several MWCNTs- 
supported MNPs catalysts have been proposed. Particularly, MWCNTs-supported RuNPs has shown more versatility in carrying out the selective catalytic processes. Recently, Yu et al., [17] investigated the $\mathrm{RuO}_{2} \mathrm{xH}_{2} \mathrm{O} / \mathrm{CNT}$ nanocatalysts for the aerobic oxidation of benzyl alcohol. Yang and co-workers [18] have prepared the RuNPs/MWCNT composite by 'wet synthesis' method and employed as a nanocatalyst for the oxidation of alcohols. They found that the RuNPs/MWCNT is highly effective, stable and reusable. However, in the common 'wet synthesis' method, several factors such as solvent, concentration of metal precursor, reducing agent, time and temperature need to be controlled carefully to obtain very good adhesion and homogeneous distribution of MNPs on MWCNTs [19-22]. Very recently, the solventless bulk synthesis so called 'dry synthesis' has been attracting greater interest due to its very simple protocol, better adhesion of MNPs on carbon materials, and has an advantage of least parameters to control [20]. In our very recent course of investigation, we prepared CuO/MWCNT [23], GNP-RuNRs [24], GNS-RuNPs [25] and $\mathrm{RuO}_{2} / \mathrm{SWCNT}$ [26] by a simple 'dry synthesis' method. Also, we found that the resultant composites are highly active as nanocatalysts in the various organic transformations. Encouraged by these results, we presumed that the $\mathrm{RuO}_{2} / \mathrm{MWCNT}^{\mathrm{N}}$ composite prepared by 'dry synthesis' method would also exhibit a good catalytic activity for the reduction of carbonyl compounds. Herein, we report the 'dry synthesis' of $\mathrm{RuO}_{2} / \mathrm{MWCNT}$ and its catalytic activity towards reduction of carbonyl compounds. Chemoselectivity, heterogeneity and stability of the $\mathrm{RuO}_{2}$ /MWCNT were also examined. The used catalyst was separated out from the reaction and reused in the same reaction as well as in the aerial oxidation of alcohols. The selective oxidation of alcohols is one of the very essential transformations in organic synthesis and also the oxygenated products are extremely valuable in chemical industries 
[27-29]. Mainly, Ru-catalyzed aerial oxidation of alcohols has been attracting a great deal of attention due to its higher activity and selectivity [30-32].

\section{Experimental}

\subsection{Materials and characterization}

High purity MWCNTs with diameter ranging from 15 to $20 \mathrm{~nm}$ were used. The MWCNTs were produced in large scale through the optimal combination of chemical vapor deposition synthetic method, and subsequent thermal treatment at $2800^{\circ} \mathrm{C}$ in an argon atmosphere [33]. $\mathrm{Ru}(\mathrm{acac})_{3}(97 \%), \mathrm{H}_{2} \mathrm{SO}_{4}(98 \%), \mathrm{HNO}_{3}(70 \%)$ and $\mathrm{HCl}(70 \%)$ were purchased from Wako pure chemicals, Japan. All other chemicals were purchased from Aldrich and used as received.

The surface morphology of the $\mathrm{RuO}_{2}$ /MWCNT was investigated by TEM (JEM-2100 JEOL Japan) with accelerating voltage of $120 \mathrm{kV}$. The weight percentage and homogeneous distribution of $\mathrm{RuO}_{2} \mathrm{NPs}$ in the $\mathrm{RuO}_{2} / \mathrm{MWCNT}$ were confirmed by SEM-EDS [Hitachi (model3000H) Scanning Electron Microscope]. The same field of view was then scanned using an EDS spectrometer to acquire a set of $\mathrm{X}$-ray maps for $\mathrm{Ru}, \mathrm{C}$ and $\mathrm{O}$ using $1 \mathrm{~ms}$ point acquisition for approximately one million counts. The interaction of $\mathrm{RuO}_{2} \mathrm{NPs}_{\text {with }} \mathrm{MWCNTs}$ was examined by Raman spectrometer (Hololab 5000, Kaiser Optical Systems Inc., USA) using argon laser at 532 nm with a Kaiser holographic edge filter. WAXD experiments were performed at room temperature using a Rotaflex RTP300 (Rigaku Co., Japan) diffractometer at $50 \mathrm{kV}$ and $200 \mathrm{~mA}$. Nickel-filtered $\mathrm{Cu} \mathrm{K \alpha}$ radiation $\left(10<2 \theta<80^{\circ}\right)$ was used for the measurements. To confirm the chemical state of $\mathrm{Ru}$ in the $\mathrm{RuO}_{2} / \mathrm{MWCNT}$, XPS spectrum was recorded in Kratos Axis-Ultra DLD model instrument. Before the XPS analysis, the sample $\left(\mathrm{RuO}_{2} / \mathrm{MWCNT}\right)$ was irradiated 
under $\mathrm{Mg} \mathrm{K} \alpha$ ray source. The specific surface area of the $\mathrm{RuO}_{2} / \mathrm{MWCNT}$ was measured by BET surface area analyzer (Micromeritics-Pulse Chemisorb 2700). Prior to the measurement, the sample was degassed for $2 \mathrm{~h}$ in $\mathrm{N}_{2}$ atmosphere at $200^{\circ} \mathrm{C}$ by using the degassing unit [Micromeritics-Desorb 2300 A]. Shimadzu-2010 Gas chromatograph (GC) was used to analyze the reaction mixture.

\subsection{Dry synthesis of $\mathrm{Ru} \mathrm{O}_{2} / \mathrm{MWCNT}$}

In a typical experiment, $0.5 \mathrm{~g}$ of pure MWCNTs were chemically treated with a 3:1 mixture of conc. $\mathrm{H}_{2} \mathrm{SO}_{4}$ and conc. $\mathrm{HNO}_{3}$, and then the mixture was sonicated at $40^{\circ} \mathrm{C}$ for $3 \mathrm{~h}$ in ultrasonic bath. After cooling to $25^{\circ} \mathrm{C}$, the solution was diluted with $500 \mathrm{~mL}$ of deionized water and then vacuum-filtered through a filter paper of $0.65 \mu \mathrm{m}$ porosity. The resultant solid mass $(f-$ MWCNTs) was frequently washed with deionized water until the $\mathrm{pH}$ became neutral and then dried in vacuo at $60^{\circ} \mathrm{C}$. Then, $0.13 \mathrm{~g}$ of $\mathrm{Ru}(\mathrm{acac})_{3}$ was added into $0.5 \mathrm{~g}$ of $f$-MWCNTs and mixed well by a mortar and pestle. The homogeneous mixture of $f$-MWCNTs and $\mathrm{Ru}(\mathrm{acac})_{3}$ was obtained in 13-15 minutes. Finally, the mixture was calcinated under $\mathrm{N}_{2}$ atmosphere at $350^{\circ} \mathrm{C}$ for $3 \mathrm{~h}$ in a muffle furnace. Fig. 1 shows schematic illustration of the procedure for the preparation of $\mathrm{RuO}_{2} / \mathrm{MWCNT}$.

\subsection{Transfer hydrogenation of carbonyl compounds}

In a typical procedure, a $5 \mathrm{mg}(0.77 \mathrm{~mol} \%)$ of $\mathrm{RuO}_{2} / \mathrm{MWCNT}$ and $80 \mathrm{mg}(2 \mathrm{mmol})$ of $\mathrm{NaOH}$ were stirred with $5 \mathrm{~mL}$ of $i-\mathrm{PrOH}$ taken in an ace pressure tube equipped with a stirring bar. Then the substrate $(1 \mathrm{mmol})$ was added to the stirring solution and then the mixture was heated at $82^{\circ} \mathrm{C}$. The completion of the reaction was monitored by GC. After the reaction, the 
catalyst was separated out from the reaction mixture by simple centrifugation and the products and unconverted reactants were analyzed by GC without any purification. Selectivity of the product for each reaction was also calculated. Finally, the separated $\mathrm{RuO}_{2} / \mathrm{MWCNT}$ was washed well with diethyl ether followed by drying in an oven at $60^{\circ} \mathrm{C}$ for $5 \mathrm{~h}$ and it was reused for the subsequent transfer hydrogenation of carbonyl compounds to investigate the reusability of the $\mathrm{RuO}_{2} / \mathrm{MWCNT}$.

\subsection{Aerial oxidation of alcohols}

$5 \mathrm{mg}$ of $r-\mathrm{RuO}_{2} / \mathrm{MWCNT}(0.68 \mathrm{~mol} \%)$ was stirred with $3 \mathrm{~mL}$ of toluene taken in a round-bottomed flask equipped with a condenser and a magnetic stirrer. The substrate (1 mmol) was added to the stirring solution and then the mixture was refluxed at $110^{\circ} \mathrm{C}$ under atmospheric pressure of air. The completion of the reaction was checked by GC. After the reaction, the $r$ $\mathrm{RuO}_{2} / \mathrm{MWCNT}$ was separated out from the reaction mixture by simple centrifugation and the products and unconverted reactants were analyzed by GC without any purification. Selectivity of the product for each reaction was also calculated.

\subsection{Product confirmation and analysis}

In order to confirm the formation of the product, samples of both reactant and products were dissolved in ethyl acetate and then analyzed by GC. GC was equipped with 5\% diphenyl and $95 \%$ dimethyl siloxane, Restek-5 capillary column $(0.32 \mathrm{~mm}$ dia, $60 \mathrm{~m}$ in length) and a flame ionization detector (FID). $\mathrm{N}_{2}$ was used as a carrier gas. The initial column temperature was increased from 60 to $150^{\circ} \mathrm{C}$ at the rate of $10^{\circ} \mathrm{C} / \mathrm{min}$ and then to $220^{\circ} \mathrm{C}$ at the rate of $40^{\circ} \mathrm{C} / \mathrm{min}$. 
During the product analysis, the temperatures of the FID and injection port were kept constant at 150 and $250^{\circ} \mathrm{C}$, respectively.

\section{Results and discussion}

\subsection{Characterization of $\mathrm{Ru} \mathrm{O}_{2} / \mathrm{MWCNT}$}

The surface morphology of the $\mathrm{RuO}_{2} / \mathrm{MWCNT}$ was investigated in detail by using TEM analysis. Fig. 2 shows the TEM images [Fig. 2(i-v)] of $\mathrm{RuO}_{2} / \mathrm{MWCNT}$ and the particle sizedistribution histogram of $\mathrm{RuO}_{2} \mathrm{NPs}$ [Fig. 2(vi)] in the $\mathrm{RuO}_{2} / \mathrm{MWCNT}$. As can be seen from Fig. 2(i-v), ultra fine and homogeneously dispersed $\mathrm{RuO}_{2} \mathrm{NPs}$ were externally attached on the surface of MWCNTs with a very narrow particle size distribution. The size distribution histogram of $\mathrm{RuO}_{2} \mathrm{NPs}$ [Fig. 2(vi)] confirmed that the diameter of $\mathrm{RuO}_{2} \mathrm{NPs}$ ranges from 0.5 to $4 \mathrm{~nm}$, with a mean diameter of $1.8 \mathrm{~nm}$. Worth mentioning that there was no free $\mathrm{RuO}_{2} \mathrm{NPs}$ were observed in the background of the TEM images [Fig. 2(iv-v)], which showed a complete utilization of the $\mathrm{RuO}_{2}$ NPs. Moreover, FE-SEM images (Fig. S1 in supporting information) were also taken for the $\mathrm{RuO}_{2} / \mathrm{MWCNT}$ and found that a very small $\mathrm{RuO}_{2} \mathrm{NPs}$ are well dispersed and externally attached on the surface of MWCNTs. Subsequently, the specific surface area of the $\mathrm{RuO}_{2} / \mathrm{MWCNT}$ was determined by BET analysis. Interestingly, a high specific surface area of $189.3 \mathrm{~m}^{2} \mathrm{~g}^{-1}$ with a pore volume of $0.898 \mathrm{~cm}^{3} \mathrm{~g}^{-1}$ and a BJH desorption average pore diameter of $186.98 \AA$ was found. In addition, the surface area per unit mass $(S)$ of $\mathrm{RuO}_{2} \mathrm{NPs}$ is calculated to be $478.1 \mathrm{~m}^{2} \mathrm{~g}^{-1}$ based on the equation $S=6000 /(\rho \times d)$ [34], where $d$ is the mean diameter, and $\rho$ is the density of $\mathrm{RuO}_{2}\left(6.97 \mathrm{~g} \mathrm{~cm}^{-3}\right)$.

In order to determine the weight percentage of $\mathrm{Ru}$ in $\mathrm{RuO}_{2} / \mathrm{MWCNT}$ and to inspect the homogeneous distribution of $\mathrm{RuO}_{2} \mathrm{NPs}$ on MWCNTs, SEM-EDS and their corresponding 
elemental mapping images were taken for $\mathrm{RuO}_{2} / \mathrm{MWCNT}$ (Fig. 3). The weight percentage of $\mathrm{Ru}$ in $\mathrm{RuO}_{2} / \mathrm{MWCNT}$ was $7.97 \mathrm{wt} \%$, as determined by EDS analysis [Fig. 3(ii)]. Fig. 3(iv) and (v) shows that the distribution of $\mathrm{RuO}_{2} \mathrm{NPs}$ in $\mathrm{RuO}_{2} / \mathrm{MWCNT}$ was homogeneous. As seen from Fig 3(iii), (iv) and (v), the $\mathrm{RuO}_{2} / \mathrm{MWCNT}$ contains carbon, ruthenium and oxygen elements only; it indicates that the proposed method (dry synthesis) is reliable and effective.

XPS spectra were recorded for MWCNTs (a), $f$-MWCNTs $(\mathbf{b})$ and $\mathrm{RuO}_{2} / \mathrm{MWCNT}(\mathbf{c})$ to study the formation of oxygen functional groups on MWCNTs, and the chemical state of Ru in $\mathrm{RuO}_{2} / \mathrm{MWCNT}$ (Fig. 4 and Fig. 5). As expected, all the three samples (a, b and $\mathbf{c}$ ) demonstrated a $\mathrm{C}$ 1s peak and $\mathrm{O} 1 \mathrm{~s}$ peak at 284.4 and $532.5 \mathrm{eV}$, respectively (Fig. S2 in supporting information). Referring Fig. 4(i), the binding energy (BE) of the $\mathrm{C}-\mathrm{C}$ and $\mathrm{C}-\mathrm{H}$ bonds was observed at $284.5-285 \mathrm{eV}$ and the peaks at $285.1,285.5,286.6$ and $288.5 \mathrm{eV}$ were attributed to $\mathrm{C}-\mathrm{OH},-\mathrm{C}-\mathrm{O}-\mathrm{C}-, \mathrm{C}=\mathrm{O}$ and $-\mathrm{COOH}$ groups, respectively [35]. Moreover, the deconvolution of O 1s spectra of $f$-MWCNTs [Fig. 4(ii)] resulted in five peaks located at 529.6, 530.7, 531.5, 532.2 and $533.5 \mathrm{eV}$, which were assigned to the $\mathrm{C}=\mathrm{O},-\mathrm{COOH}, \mathrm{C}-\mathrm{OH},-\mathrm{C}-\mathrm{O}-\mathrm{C}-$ and $\mathrm{H}_{2} \mathrm{O}$ respectively [36]. This result confirmed the successful creation of oxygen functional groups on the surface of MWCNTs. The two main reasons for the functionalization of MWCNTs are; (i) to make the MWCNTs hydrophilic for the homogenous decoration of $\mathrm{RuO}_{2} \mathrm{NPs}$ on MWCNTs, and (ii) to create additional nucleation centers for the better adhesion of $\mathrm{RuO}_{2} \mathrm{NPs}$ on MWCNTs. Moreover, these functional groups play a bridging role between the $\mathrm{RuO}_{2} \mathrm{NPs}$ and MWCNTs; consequently, good dispersion and strong attachment of $\mathrm{RuO}_{2} \mathrm{NPs}$ on MWCNTs were achieved [37]. The XPS spectrum of the $\mathrm{RuO}_{2} / \mathrm{MWCNT}$ in Ru 3p region [Fig. 5(ii)] showed $\mathrm{BE}$ of $\mathrm{Ru}$ $3 p_{3 / 2}$ at $462.5 \mathrm{eV}$ and $\mathrm{Ru} 3 \mathrm{p}_{1 / 2}$ at $485.2 \mathrm{eV}$, which corresponded to the photoemission from $\mathrm{RuO}_{2}$ $\left(\mathrm{Ru}^{4+}\right)$ [37]. In Fig. 5(i), the XPS spectrum of the $\mathrm{RuO}_{2} / \mathrm{MWCNT}$ show $\mathrm{Ru} 3 \mathrm{~d}_{5 / 2}$ peak at 280.8 
$\mathrm{eV}$ which is also attributed to the photoemission from $\mathrm{RuO}_{2}$ [37]. The overlapping of the $\mathrm{C} 1 \mathrm{~s}$ and the $\mathrm{Ru} 3 \mathrm{~d}_{3 / 2}$ peaks at $\sim 285 \mathrm{eV}$ makes it complicated to assign the $\mathrm{BE}$ of $\mathrm{Ru} 3 \mathrm{~d}_{3 / 2}$ [Fig. 5(i)]. Fig. 6(i) shows the XRD patterns of $\mathrm{RuO}_{2} / \mathrm{MWCNT}$. The diffraction peaks were observed at $26.5^{\circ}$ and $42.4^{\circ}$, corresponding to the (002) and (100) crystal planes of MWCNTs, respectively, which attributed to the hexagonal graphite structures of MWCNTs [24]. In addition to that, $\mathrm{RuO}_{2} / \mathrm{MWCNT}$ showed signature patterns at $27.5^{\circ}, 34.9^{\circ}, 39.9^{\circ}$ and $54.5^{\circ}$ corresponding to the typical crystal faces (110), (101), (200) and (220) of $\mathrm{RuO}_{2}$ (JCPDS 21-1172), respectively [24]. The broadness of the diffraction peaks confirmed that the $\mathrm{RuO}_{2} \mathrm{NPs}$ in $\mathrm{RuO}_{2} / \mathrm{MWCNT}$ are in nanocrystalline nature.

The nature of interaction between $\mathrm{RuO}_{2} \mathrm{NPs}$ and MWCNTs was investigated by comparing the Raman spectra of $f$-MWCNTs (a) and $\mathrm{RuO}_{2} / \mathrm{MWCNT}$ (b) [Fig. 6(ii)]. As expected, samples $\mathbf{a}$ and $\mathbf{b}$ showed two characteristic peaks at 1345 and $1580 \mathrm{~cm}^{-1}$, corresponding to the $s p^{3}$ - and $s p^{2}$-hybridized carbons which authenticated the disordered graphite (D band) and the ordered state graphite (G band) of MWCNTs [38]. Well known that, the ratio of $\mathrm{D}$ and $\mathrm{G}$ bands $\left(I_{\mathrm{D}} / I_{\mathrm{G}}\right)$ intensities is often used as a diagnostic tool to evaluate the defect concentration in MWCNTs. Therefore, $I_{\mathrm{D}} / I_{\mathrm{G}}$ was calculated for the samples a and $\mathbf{b}$ [Fig. 6(ii)]. The data revealed that $\mathrm{RuO}_{2} \mathrm{NPs}$ were strongly attached on the surface of MWCNTs as the $I_{\mathrm{D}} / I_{\mathrm{G}}$ ratio was reasonably high for $\mathrm{RuO}_{2} / \mathrm{MWCNT}$ (1.4579) in comparison to that of $f$-MWCNTs (1.4113). In addition, negative shift was also observed in the $\mathrm{D}$ band $\left(1347\right.$ to $\left.1341 \mathrm{~cm}^{-1}\right)$ and $\mathrm{G}$ band (1580 to $1576 \mathrm{~cm}^{-1}$ ) for $\mathrm{RuO}_{2} / \mathrm{MWCNT}$, which indicates that $\mathrm{RuO}_{2} \mathrm{NPs}_{\text {interacted strongly }}$ on the surface of the MWCNTs [39]. Worth mentioning that, the absence of peaks around 1700 $\mathrm{cm}^{-1}$ in the Raman spectra of $\mathbf{a}$ and $\mathbf{b}$ suggested that the present process produces fairly pure MWCNTs. 


\subsection{Optimization of reaction conditions}

In order to get an effective conversion of carbonyl compounds to alcohols, reaction parameters such as base, amount of base, amount of catalyst, temperature and reaction time were optimized (Table 1). The conversion of acetophenone (model substrate) was checked through GC. At first, transfer hydrogenation of acetophenone was investigated with different bases such as $\mathrm{KOH}, \mathrm{NaOH}, \mathrm{K}_{2} \mathrm{CO}_{3}$ or $\left(\mathrm{CH}_{3}\right)_{3} \mathrm{COK}$. Among them, $\mathrm{NaOH}$ was found to be the efficient since it gave an excellent yield of $96 \%$ (Table 1, entries 1-4). The amount of base also played a crucial role in the present $\mathrm{RuO}_{2} / \mathrm{MWCNT}$ system (Table 1, entries 2, 5-7); a 2 mmol of base was required to achieve the excellent yield (Table 1, entry 2). Similarly, the amount of catalyst was optimized; as a consequence, a very lower conversion of $13 \%$ was obtained in the absence of $\mathrm{RuO}_{2} / \mathrm{MWCNT}$ (Table 1 , entry 8$)$. Whereas addition of $5.0 \mathrm{mg}(0.71 \mathrm{~mol} \%)$ of $\mathrm{RuO}_{2} / \mathrm{MWCNT}^{-}$ yielded $96 \%$ of the product (Table 1, entry 2). Lesser amount of catalyst (2.5 mg; $0.24 \mathrm{~mol} \%$ ) was ineffective (27\%) (Table 1, entry 9) which may be due to the presence of insufficient number of active sites $\left(\mathrm{RuO}_{2}\right)$ for the substrates. Furthermore, increase of the amount of the catalyst (7.5 and $10 \mathrm{mg} ; 0.48$ and $0.96 \mathrm{~mol} \%$ ) showed no significant change in the yield (Table 1, entries $10-11)$. Hence, $5.0 \mathrm{mg}(0.77 \mathrm{~mol} \%)$ was found to be the optimum amount of the catalyst. Subsequently, reaction temperature was optimized. At the lower reaction temperatures $(27,50$ and $70^{\circ} \mathrm{C}$ ), the reactions were very slow, which gave very poor yield (Table 1, entries 12-14). But excellent yield was obtained $(96 \%)$ when the reaction is stirred at the temperature of $82^{\circ} \mathrm{C}$ (Table 1, entry 2). This might be due to faster adsorption of the substrates on $\mathrm{RuO}_{2}$ active sites at $82^{\circ} \mathrm{C}$. Progress of the reaction was monitored at every $10 \mathrm{~min}$ time interval (Table 1 , entries 15 23). No further increase in the yield after 45 min concluded that $45 \mathrm{~min}$ is the optimum reaction time (Table 1, entry 2). Worth mentioning that under the optimized reaction conditions, the 
present $\mathrm{RuO}_{2} / \mathrm{MWCNT}$ system achieved an excellent yield of $96 \%$ with a good turnover number of 125 and turnover frequency of $167 \mathrm{~h}^{-1}$. The optimized reaction conditions were adopted to extend the substrate scope.

\subsection{Extension of scope}

Benzaldehyde, substituted benzaldehydes and other substituted aldehydes were converted into the corresponding primary alcohols in excellent to moderate yields (Table 2, entries 1-10). The yield of the products was moderately affected by the substituent on the aromatic ring, but the selectivity was maintained. Initially, benzaldehyde was converted into 95\% of benzyl alcohol with $100 \%$ selectivity after $45 \mathrm{~min}$ (Table 2 , entry 1 ). But $\mathrm{HSi}(\mathrm{OMe})_{3} / \mathrm{LiOMe}$ catalytic system yielded only $85 \%$ of benzyl alcohol even after $20 \mathrm{~h}$ [40]. Electron withdrawing substituent in the phenyl ring retarded the reactivity. In evidence to this, 4-bromo (Table 2, entry 2), 2-bromo (Table 2, entry 3), 4-chloro (Table 2, entry 4) and 4-nitro benzaldehydes (Table 2, entry 6) were found to be less reactive compared to unsubstituted benzaldehyde in the present catalytic system. In contrast, the electron releasing substituent increased the reactivity. For example, 4methylbenzaldehyde was hydrogenated to form 4-methylbenzyl alcohol in 97\% yield with 100\% selectivity (Table 2, entry 5). Aldehydes with bulky substituent namely 2-naphthaldehyde and 1pyrenecarboxaldehyde were reduced to corresponding primary alcohols with lesser selectivity (82 and $80 \%$ ). The former one was converted into 2-naphthalenemethanol (51\%) after $45 \mathrm{~min}$ (Table 2, entry 7), whereas the later required $120 \mathrm{~min}$ to achieve $54 \%$ of the corresponding reduced product (Table 2, entry 8). 100\% selectivity was achieved when 3-phenylpropanal was hydrogenated to 3-phenylpropan-1-ol after $120 \mathrm{~min}$ (Table 2, entry 9). N,N-Dimethyl 
benzaldehyde yielded $75 \%$ of $N, N$-dimethylbenzyl alcohol after 45 min with $95 \%$ selectivity (Table 2, entry 10).

After the successful reduction of aldehydes to primary alcohols, ketones were converted into secondary alcohols under the same reaction conditions (Table 2, entries 1-15). Acetophenone was hydrogenated to 1-phenylethanol (96\%) with $100 \%$ selectivity after $45 \mathrm{~min}$ (Table 3, entry 1). But $\mathrm{HSi}(\mathrm{OMe})_{3} / \mathrm{LiOCMe}{ }_{2} \mathrm{CMe}_{2} \mathrm{OLi}[40]$ and $\mathrm{Au} / \mathrm{TiO}_{2}$ catalytic systems [41] required 20 and $4 \mathrm{~h}$ respectively for the complete reduction of acetophenone. In contrast to the reduction of benzaldehydes, acetophenones bearing electron withdrawing or electron releasing substituent in the phenyl ring yielded the corresponding substituted 1-phenylethanol more readily. In witness to this statement, 4-bromoacetophenone and 4-methoxyactophenone were converted into their corresponding secondary alcohols namely 4-bromo-1-phenylethanol (Table 3, entry 2) and 4-methoxy-1-phenylethanol (Table 3, entry 3) in 92 and $88 \%$ yield respectively with excellent selectivity after 45 min. But RuCs- $\beta$ (IMP-carbonyl) catalyst yielded $98 \%$ of 4-bromo1-phenylethanol and $92 \%$ of 4-methoxy-1-phenylethanol only after 48 and $36 \mathrm{~h}$ respectively [42]. Acetophenones having substituent at the ortho, meta or para position were also subjected to transfer hydrogenation. 3-Nitroacetophenone (Table 3, entry 4), 2-methylacetopheone (Table 3, entry 5) and 4-methylacetophone (Table 3, entry 6) produced corresponding 1-phenylethanol with excellent conversion, selectivity and yield. Particularly, in the reduction of 2methylacetopheone to 1-(o-tolyl)ethanol (Table 3, entry 5), the present catalytic system gave a better yield of 95\% (100\% selectivity) with an excellent TON (123) and TOF $\left(148 \mathrm{~h}^{-1}\right)$ values after only $50 \mathrm{~min}$. Whereas $\mathrm{Ru}(\mathrm{OH})_{\mathrm{x}} / \mathrm{TiO}_{2}$ system gave $82 \%$ (with $\mathrm{TON} / \mathrm{TOF}$ of $82 / 27 \mathrm{~h}^{-1}$ ) of the same product only after $3 \mathrm{~h}$ even at $90^{\circ} \mathrm{C}$ under $\mathrm{Ar}$ atmosphere [12]. Substituted benzophenone specifically 4-methoxybenzophenone was reduced to 4-methoxydiphenylmethanol (73\%) after 
45 min (Table 3, entry 7); moderate yield of the product may be due to the presence of the bulky substituent [43]. Scope of this system was also extended to aliphatic and alicyclic carbonyl compounds. Aliphatic ketones yielded the corresponding alcohols in good to excellent yields. Almost 100\% selectivity was achieved in all the cases with the yield ranging from 95 to $98 \%$ (Table 3, entries 8-10). Notably, in the reduction of less reactive 2-butanone to 2-butanol (Table 3, entry 8), the present $\mathrm{RuO}_{2} / \mathrm{MWCNT}$ system showed a better yield of $95 \%$ (100\% selectivity) when compared to GNPs- $\mathrm{RuO}_{2} \mathrm{NRs}$ system [24]. The better yield is due to the higher surface area of $\mathrm{RuO}_{2}$ /MWCNT $\left(189.3 \mathrm{~m}^{2} \mathrm{~g}^{-1}\right)$ than the GNPs-RuO 2 NRs $\left(65.17 \mathrm{~m}^{2} \mathrm{~g}^{-1}\right)$. Similarly, 2octanone gave 2-octanol in an excellent yield of 98\% (100\% selectivity) just after $1 \mathrm{~h}$ (Table 3, entry 11) whereas $\mathrm{Ru}(\mathrm{OH})_{\mathrm{x}} / \mathrm{TiO}_{2}$ system exhibited $92 \%$ yield even after $2 \mathrm{~h}$ [12]. In contrast to $\mathrm{Fe} @ \mathrm{SiO}_{2} \mathrm{Ru}$ nanocatalyst [44], alicyclic alcohols with different ring size were produced from the alicyclic ketones with $100 \%$ selectivity, but they took longer reaction times. As the ring size increases, decreased reactivity was observed (Table 3, entries 12-14). The reactivity order is cyclohexanone (92\%) > cycloheptanone (88\%) > cyclododecanone (77\%). But nickel/aluminosilicate catalyst yielded only $58 \%$ of cyclohexanone under similar reaction conditions [45]. 100\% Selectivity was accomplished when carbonyl functionality was present in the side chain of the alicyclic ring (Table 3, entry 15).

In order to illustrate the synthetic utility of the present catalytic system, some heterocyclic aldehydes and ketones were subjected to transfer hydrogenation (Table 4). 2-Acetylthiophene yielded the corresponding alcohol (97\%) after 90 min with 100\% selectivity (Table 4, entry 1). $\mathrm{RhCl}\left(\mathrm{PPh}_{3}\right)_{3}$ catalytic system gave only $4 \%$ of the same product [46]. Likewise, the present system was found to be effective in the reduction of 2 -furfuraldehyde which gave $74 \%$ of the product (Table 4, entry 2). Only $50 \%$ of the product was achieved from the reduction of 2 - 
furfuraldehyde with Pt decorated $\mathrm{Al}_{2} \mathrm{O}_{3}$ catalyst [47]. 3-Formylindol and 5-formylindol were effectively reduced to indole-3-methanol (88\%) and indole-5-methanol (96\%) respectively with very good selectivity (Table 4, entries 3 and 4). In the same way 4-(2-pyridyl)benzaldehyde gave 77\% of 4-(2-pyridyl)benzyl alcohol with $100 \%$ selectivity after 100 min (Table 4, entry 5). Worth mentioning that $\mathrm{RuO}_{2} / \mathrm{MWCNT}$ system achieved good yields (51 to 98\%) with high TON (127 to 66) and TOF (246 to $35 \mathrm{~h}^{-1}$ ) values in the transfer hydrogenation of carbonyl compounds.

\subsection{Chemoselectivity of $\mathrm{RuO}_{2} / \mathrm{MWCNT}$}

Referring table 4, the present $\mathrm{RuO}_{2} / \mathrm{MWCNT}$ catalytic system is highly chemoselective in nature. 4-Acetylbenzaldehyde was chemoselectively reduced to 1-(4(hydroxymethyl)phenyl)ethanone (Table 5, entry 1). The phenyl ring containing aldehyde and ester functional groups was subjected to transfer hydrogenation and only the aldehyde was selectively reduced to primary alcohol without affecting the ester functionality (Table 5 , entry 2 ). Similar trend was observed with the phenyl ring having ketone and acid functional groups (Table 5 , entry 3$)$.

\subsection{Effect of particle size on catalytic activity}

Particle size and surface area are important factors in any nanocatalytic system. In order to determine the effect of the $\mathrm{RuO}_{2}$ particle size on catalytic efficiency in terms of yields, another catalyst with $\mathrm{RuO}_{2}$ particle size of around 5 to $12 \mathrm{~nm}\left(b-\mathrm{RuO}_{2} / \mathrm{MWCNT}\right)$ was prepared by calcinating the mixture $\left[f\right.$-MWCNT and $\left.\mathrm{Ru}(\mathrm{acac})_{3}\right]$ under air atmosphere at $375^{\circ} \mathrm{C}$ for $3 \mathrm{~h}$ and its catalytic performance was compared with the $\mathrm{RuO}_{2} / \mathrm{MWCNT}$. At first, $b-\mathrm{RuO}_{2} / \mathrm{MWCNT}$ nanocatalyst was characterized by TEM analysis. It was found that the particle size of $\mathrm{RuO}_{2} \mathrm{NPs}$ 
was around 5 to $12 \mathrm{~nm}$ with the mean diameter of $9 \mathrm{~nm}$ [Fig. 7(i) and (ii)]. The weight percentage of $\mathrm{Ru}$ in $b-\mathrm{RuO}_{2} / \mathrm{MWCNT}$ was found to be 8.01 by using SEM-EDS analysis [Fig. 7(iii)]. XPS analysis revealed that $\mathrm{Ru}$ was present as $\mathrm{RuO}_{2}$ and hence it showed $3 \mathrm{p}_{1 / 2}$ peak at 485 $\mathrm{eV}$ and $3 \mathrm{p}_{3 / 2}$ peak at $462 \mathrm{eV}$. The surface area per unit mass $(S)$ of $b-\mathrm{RuO}_{2} / \mathrm{MWCNT}$ was found to be $88.6 \mathrm{~m}^{2} \mathrm{~g}^{-1}$. After the characterization, $b-\mathrm{RuO}_{2} / \mathrm{MWCNT}$ was used as a catalyst for the transfer hydrogenation of some carbonyl compounds (Table 6). Acetophenone was reduced to 1phenylethanol in moderate yield of $65 \%$ (Table 6, entry 1) whereas the $\mathrm{RuO}_{2} / \mathrm{MWCNT}$ system gave an excellent yield (96\%) of the desired product (Table 3, entry 1). The reactivity of aliphatic carbonyl compounds was found to be lesser in the $b-\mathrm{RuO}_{2} / \mathrm{MWCNT}$ system (Table 6 , entry 2) when compared to $\mathrm{RuO}_{2} / \mathrm{MWCNT}$ system. Similarly, reduction of alicyclic ketone produced lower yield of alicyclic alcohol with $b-\mathrm{RuO}_{2} / \mathrm{MWCNT}$ catalyst (Table 6, entry 3 ). Same kind of behavior was observed with benzaldehyde (Table 6, entry 4) and heterocyclic carbonyl compound (Table 6, entry 5). Hence, it is inferred that the excellent activity of $\mathrm{RuO}_{2} / \mathrm{MWCNT}$ compared to $b-\mathrm{RuO}_{2} / \mathrm{MWCNT}$ was mainly due to the ultra-fine structure of the $\mathrm{RuO}_{2} \mathrm{NPs}$.

\subsection{Heterogeneity and reusability of $\mathrm{RuO}_{2} / \mathrm{MWCNT}$}

In order to understand the heterogeneous nature of the $\mathrm{RuO}_{2} / \mathrm{MWCNT}$, a hot filtration test was performed. In a typical test, reduction of acetophenone was carried out under optimized conditions for $20 \mathrm{~min}$ and the yield of 1-phenylethanol determined by GC was $45 \%$. Subsequently, the $\mathrm{RuO}_{2} / \mathrm{MWCNT}$ was filtered out from the reaction mixture (after $20 \mathrm{~min}$ ) and then the reaction was continued without the catalyst for $60 \mathrm{~min}$. The progress of the reaction was monitored at each 10 min intervals; the results are shown in Fig. 8(i). It can be seen that there 
was no significant change in the yield in the absence of the catalyst even after extended reaction time (after $60 \mathrm{~min}$ ), which indicated that the reaction proceeded mainly due to the catalytic effect of $\mathrm{RuO}_{2} / \mathrm{MWCNT}$ and also there was no leaching of Ru from the $\mathrm{RuO}_{2} / \mathrm{MWCNT}$.

Since reusability is one of the important features of the nanocatalysts, it was also tested for the $\mathrm{RuO}_{2} / \mathrm{MWCNT}$. After the first cycle, the catalyst was separated out from the reaction mixture by simple centrifugation, washed well with diethyl ether, dried at $150^{\circ} \mathrm{C}$, and then reused in the second cycle. Likewise, the catalytic cycle was repeated for 8 times and the yield monitored by $\mathrm{GC}$ is shown in Fig. 8(ii). Interestingly, the $\mathrm{RuO}_{2} / \mathrm{MWCNT}$ system gave an excellent yield of $87 \%$ (100\% selectivity) with high TON (113) and TOF (151 $\left.\mathrm{h}^{-1}\right)$ values at the $8^{\text {th }}$ cycle, which indicated its good reusability. Moreover, the reused catalyst $\left(u-\mathrm{RuO}_{2} / \mathrm{MWCNT}\right)$

was further investigated by TEM, SEM-EDS and XPS analyses (Fig. S3 in supporting information). In comparison to the fresh $\mathrm{RuO}_{2} / \mathrm{MWCNT}$, no significant change in the morphology, size, shape, chemical state and weight percentage of Ru was observed for the $u$ $\mathrm{RuO}_{2} / \mathrm{MWCNT}$. Hence, it is obvious that the $\mathrm{RuO}_{2} / \mathrm{MWCNT}$ is physically as well as chemically stable.

\subsection{Versatility of $\mathrm{RuO}_{2} / \mathrm{MWCNT}$}

Inspired by the high stability of the $\mathrm{RuO}_{2} / \mathrm{MWCNT}$, the $u-\mathrm{RuO}_{2} / \mathrm{MWCNT}$ was further applied in oxidation reactions. Initially, the $u-\mathrm{RuO}_{2} / \mathrm{MWCNT}$ was washed with diethyl ether and dried in an oven at $60^{\circ} \mathrm{C}$ for $5 \mathrm{~h}$. Then the washed $u-\mathrm{RuO}_{2} / \mathrm{MWCNT}$ was calcinated under $\mathrm{N}_{2}$ atmosphere at $450^{\circ} \mathrm{C}$ for $6 \mathrm{~h}$ in a muffle furnace to obtain ruthenium oxide nanorods $\left(\mathrm{RuO}_{2} \mathrm{NRs}\right)$ hybrid MWCNTs. The resultant hybrid $\left(r-\mathrm{RuO}_{2} / \mathrm{MWCNT}\right)$ was well characterized and it was used as a catalyst for the aerial oxidation of alcohols. Fig. 9 shows the TEM images [Fig. 10(i- 
iii)], SEM and the corresponding EDS spectrum [Fig. 10(iv) and (v)] and XPS spectrum [Fig. 10(vi)] of $r-\mathrm{RuO}_{2} / \mathrm{MWCNT}$. The TEM images confirmed the external attachment of very fine and well dispersed $\mathrm{RuO}_{2} \mathrm{NRs}$ on the MWCNTs. The length and diameter of $\mathrm{RuO}_{2} \mathrm{NRs}$ were found in the range of 20-40 and 7-14 nm, respectively. The weight percentage of $\mathrm{Ru}$ in the $r$ $\mathrm{RuO}_{2} / \mathrm{MWCNT}$ was found to be 6.92 from SEM-EDS analysis. In the XPS spectrum of $r$ $\mathrm{RuO}_{2} / \mathrm{MWCNT}$ [Fig. 10(vi)], the BE of Ru $3 \mathrm{p}_{3 / 2}$ at $462.4 \mathrm{eV}$ and $\mathrm{Ru} 3 \mathrm{p}_{1 / 2}$ at $485.1 \mathrm{eV}$ were attributed to the photoemission from $\mathrm{RuO}_{2}\left(\mathrm{Ru}^{4+}\right)$ [48]. It was found that the $r-\mathrm{RuO}_{2} / \mathrm{MWCNT}$ is highly efficient for the aerial oxidation of alcohols (Table 7). In the preliminary test, fortunately, 1-phenylethanol showed a very high conversion of $98 \%$ with $100 \%$ selectivity (Table 7 , entry 1). Inspired by this result, the scope of the catalytic system was extended to a wide range of aromatic, aliphatic, alicyclic and heterocyclic alcohols (Table 7). Benzyl alcohol was converted into benzaldehyde in $91 \%$ yield (94\% selectivity) without any over oxidation to benzoic acid (Table 7, entry 2). $\mathrm{Cu} / \mathrm{AlO}(\mathrm{OH})$ catalytic system took $7 \mathrm{~h}$ for the complete oxidation of benzyl alcohol even in presence of a strong oxidizing agent $\left(\mathrm{H}_{5} \mathrm{IO}_{6}\right)$ [49]. In the oxidation of less reactive 2-octanol, the present catalytic system gave a better yield of $78 \%$ with $100 \%$ selectivity compared to $\mathrm{RuO}_{2}$-FAU catalytic system (Table 7, entry 3) [28]. Moreover, less reactive cyclopentanol was also converted into cyclopentanone in better yield of $70 \%$ whereas $\mathrm{Au} / \mathrm{Fe}_{3} \mathrm{O}_{4} @ \mathrm{SiO}_{2}$-catalyzed reaction gave only $42 \%$ yield (Table 7, entry 4) [50]. The $r$ $\mathrm{RuO}_{2} / \mathrm{MWCNT}$ catalytic system showed comparatively lesser yields when compared with the commercial Ru/Al $\mathrm{O}_{3}$ catalytic system [30]. Interestingly, the $r-\mathrm{RuO}_{2} / \mathrm{MWCNT}$ catalytic system was also adopted for the heterocyclic alcohols. For example, 1-furyl ethanol yielded 1furylethanone in $62 \%$ yield with a moderate selectivity of $80 \%$ (Table 7 , entry 5 ). The results 
concluded that the $r$ - $\mathrm{RuO}_{2} / \mathrm{MWCNT}$ effectively catalyzed oxidation of various alcohols; this confirmed that the proposed catalyst $\left(\mathrm{RuO}_{2} / \mathrm{MWCNT}\right)$ was stable and highly versatile.

\section{Conclusions}

In summary, a very simple 'dry synthesis' method was used to decorate the $\mathrm{RuO}_{2} \mathrm{NPs}$ on MWCNTs. The $\mathrm{RuO}_{2} / \mathrm{MWCNT}$ catalyst exhibited excellent catalytic activity, chemoselectivity, stability, heterogeneity and reusability in the transfer hydrogenation of carbonyl compounds. Interestingly, the present $\mathrm{RuO}_{2} / \mathrm{MWCNT}$ system tolerated a wide range of functional groups. The excellent yield of the products is mainly due to the smaller particle size of the $\mathrm{RuO}_{2} \mathrm{NPs}$. Moreover, the versatility of the $\mathrm{RuO}_{2} / \mathrm{MWCNT}$ was realized from the excellent activity of $r$ $\mathrm{RuO}_{2} / \mathrm{MWCNT}$ catalyst in the aerial oxidation of alcohols. 


\section{References}

[1] G. Zassinovich, G. Mestroni, S. Gladiali, Chem. Rev. 92 (1992) 1051-1069.

[2] D.A. Evans, S.G. Nelson, M.R. Gagne, A.R. Muci, J. Am. Chem. Soc. 115 (1993) 98009801.

[3] R. Noyori, S. Hashiguchi, Acc. Chem. Res. (30) 1997 97-102.

[4] R.A.W. Johnstone, A.H. Wilby, Chem. Rev. 85 (1985) 129-170.

[5] B. Gottfried, J.N. Terry, Chem. Rev. 74 (1974) 567-580.

[6] M. Shiding, L. Zhimin, H. Buxing, H. Jun, S. Zhenyu, Z. Jianling, J. Tao, Angew. Chem. Int. Ed. 45 (2006) 266-269.

[7] B.F.G. Johnson, Coord. Chem. Rev. 190-192 (1999) 1269-1285.

[8] I. Arindam, M. Niladri, M. Prasenjit, B. Sumit, K.L. Goutam, J. Catal. 284 (2011) 176183.

[9] L. Fang, L. Jing, X. Jie, J. Mol. Catal. A: Chem. 271 (2007) 6-13.

[10] B. Baruwati, V. Polshettiwar, R.S Varma, Tetrahedron Lett. 50 (2009) 1215-1218.

[11] M.L. Kantam, R.S. Reddy, U. Pal, B. Sreedhar, S. Bhargavab, Adv. Synth. Catal. 350 (2008) 2231-2235.

[12] K. Yamaguchi, T. Koike, J.W. Kim, Y. Ogasawara, N Mizuno, Chem. Eur. J. 14 (2008) 11480-11487.

[13] E. Auer, A. Freund, J. Pietsch, T. Tacke, Appl. Catal. A: Gen. 173 (1998) 259-271.

[14] S. Philippe, C. Eva, Chem. Cat. Chem. 2 (2010) 1-47.

[15] S. Philippe, C. Massimiliano, K. Philippe, Appl. Catal. A: Gen. 253 (2003) 337-358.

[16] J.M. Planeix, N. Coustel, B. Coq, V. Bretons, P.S. Kumbhar, R.D.P. Geneste, P. Bernier, P.M. Ajayan, J. Am. Chem. Soc. 116 (1994) 7935-7936. 
[17] H. Yu, X. Fu, C. Zhou, F. Peng, H. Wang, J. Yang, Chem. Commun. (2009) 2408-2410.

[18] X. Yang, X. Wang, J. Qiu, Appl. Catal. A: Gen. 382 (2010) 131-137.

[19] X.R. Ye, Y. Lin, C. Wang, M.H. Engelhard, Y. Wang, C.M. Wai, J. Mater. Chem. 14 (2004) 908-913.

[20] B. Wu, Y. Kuang, X. Zhang, J. Chen, Nano Today 6 (2011) 75-90.

[21] T. Vassilios, G. Vasilios, O. Eudokia, K. Michael, P. Dimitrios, Carbon 44 (2006) 848853.

[22] Y. Lin, K.A. Watson, M.J. Fallbach, S. Ghose, J.G. Smith, D.M. Delozier, W. Cao, R.E. Crooks, J.W. Connell, ACS Nano 3 (2009) 871-884.

[23] M. Gopiraman, S. Ganesh Babu, Z. Khatri, W. Kai, Y.A. Kim, M. Endo, R. Karvembu, I.S. Kim, Carbon 62 (2013) 135-148.

[24] M Gopiraman, S. Ganesh Babu, Z. Khatri, K. Wei, E. Morinobu, R. Karvembu, I.S. Kim, Catal. Sci. Technol. 3 (2013) 1485-1489.

[25] M. Gopiraman, S.Ganesh Babu, Z. Khatri, K. Wei, Y.A. Kim, M. Endo, R. Karvembu, I.S. Kim, J. Phys. Chem. C 117 (2013) 23582-23596.

[26] M. Gopiraman, R. Karvembu, I. S. Kim, ACS Catal. 4 (2014) 2118-2129.

[27] W. E. Billups, B.E. Arney, L.J. Lin, J. Org. Chem. 49 (1984) 3436-3437.

[28] B.Z. Zhan, A. Thompson, Tetrahedron 60 (2004) 2917-2935.

[29] B. Michele, G. Pierre, Catal. Today 57 (2000) 127-141.

[30] K. Yamaguchi, N. Mizuno, Chem. Eur. J. 9 (2003) 4353-4361.

[31] B.Z. Zhan, M.A. White, T.K. Sham, J.A. Pincock, R.J. Doucet, K.V. Ramana Rao, K.N. Robertson, T.S. Cameron J. Am. Chem. Soc. 125 (2003) 2195-2199. 
[32] D.V. Bavykin, A.A. Lapkina, P.K. Plucinski, J.M. Friedrich, F.C. Walsh, J. Catal. 235 (2005) 10-17.

[33] G.G. Wildgoose, C.E. Banks, R.G. Compton, Small 2 (2006) 182-93.

[34] J. Lu, I. Do, L.T. Drzal, R.M. Worden, I. Lee, ACS Nano 2 (2008) 1825-1832.

[35] O. Akhavan, Carbon 48 (2010) 509-519.

[36] T. Kuila, S. Bhadra, D. Yao, N.H. Kim, S. Bose, J.H. Lee, Prog. Polym. Sci. 35 (2010) $1350-1375$.

[37] N. Chakroune, G. Viau, S. Ammar, L. Poul, D. Veautier, M.M. Chehimi, C. Mangeney, F. Villain, F. Fievet, Langmuir 21 (2005) 6788-6796.

[38] M.S. Dresselhaus, G. Dresselhaus, R. Saito, A. Jorio, Phys. Rep. 409 (2005) 47-99.

[39] A.G. Souza Filho, V. Meunier, M. Terrones, B.G. Sumpter, E.B. Barros, F. VillalpandoPaez, J.M. Filho, Y.A. Kim, H. Muramatsu, T. Hayashi, M. Endo, M.S. Dresselhaus, Nano Lett. 7 (2007) 2383-2388.

[40] A. Hosomi, H. Hayashida, S. Kohra, Y.J. Tominaga, J. Chem. Soc. Chem. Commun. $1986(1986) 1411-1412$.

[41] S.Z. Fang, H. Lin, N. Ji, C. Yong, H.Y. He, F.N. Kang, Chem. Commun. (2008) 35313533.

[42] M.L. Kantam, B.P.C. Rao, B.M. Choudary, B. Sreedhar, Adv. Synth. Catal. 348 (2006) 1970-1976.

[43] R. Noyori, T. Ohkuma, Angew. Chem. Int. Ed. 40 (2001) 40-73.

[44] R.B. Nasir Baig, R.S. Varma, ACS Sust. Chem. Eng. 1 (2013) 805-809.

[45] N. Neelakandeswari, G. Sangami, P. Emayavaramban, S. Ganesh Babu, R. Karvembu, N. Dharmaraj, J. Mol. Catal. A: Chem. 356 (2012) 90-99. 
[46] K. Bogar, P. Krumlinde, Z. Bacsik, N. Hedin, J.E. Backvall, J.R. Ruiz, C.J. Sanchidrian, J.M. Hidalgo, J.M. Marinas, Eur. J. Org. Chem. 2011 (2011) 4409-4414.

[47] J. Kijenski, P. Winiarek, T. Paryjczak, A. Lewicki, A. Mikołajska, Appl. Catal. A: Gen. 233 (2002) 171-182.

[48] M. Gopiraman, H. Bang, S. Ganesh Babu, K. Wei, R. Karvembu, I.S. Kim, Catal. Sci. Technol. 4 (2014) 2099-2106.

[49] S. Ganesh Babu, P.A. Priyadarsini, R. Karvembu, Appl. Catal. A: Gen. 392 (2011) 218224.

[50] R.L. Oliveira, P.K. Kiyohara, L.M. Rossi, Green Chem. 12 (2010) 144-149. 


\section{Table 1}

Optimization of the reaction conditions for the transfer hydrogenation of acetophenone ${ }^{a}$.

\begin{tabular}{|c|c|c|c|c|c|c|c|}
\hline entry & base $^{b}$ & $\begin{array}{c}\text { amount of } \\
\text { base } \\
(\mathrm{mmol})\end{array}$ & $\begin{array}{c}\text { amount of } \\
\text { catalyst } \\
(\mathrm{mol} \%)\end{array}$ & $\begin{array}{c}\text { temperature } \\
\left({ }^{\circ} \mathrm{C}\right)\end{array}$ & $\begin{array}{l}\text { time } \\
(\min )\end{array}$ & $\begin{array}{l}\text { yield }^{c} \\
(\%)\end{array}$ & $\begin{array}{c}\text { TON/ } \\
\left(\mathrm{TOF} \mathrm{h}^{-1}\right)^{d}\end{array}$ \\
\hline 1 & $\mathrm{KOH}$ & 2 & 0.77 & 82 & 45 & 26 & $34 / 45$ \\
\hline 2 & $\mathrm{NaOH}$ & 2 & 0.77 & 82 & 45 & 96 & $125 / 167$ \\
\hline 3 & $\mathrm{~K}_{2} \mathrm{CO}_{3}$ & 2 & 0.77 & 82 & 45 & 15 & $20 / 27$ \\
\hline 4 & $\left(\mathrm{CH}_{3}\right)_{3} \mathrm{COK}$ & 2 & 0.77 & 82 & 45 & 39 & $51 / 68$ \\
\hline 5 & $\mathrm{NaOH}$ & 1 & 0.77 & 82 & 45 & 41 & $53 / 71$ \\
\hline 6 & $\mathrm{NaOH}$ & 1.5 & 0.77 & 82 & 45 & 56 & $73 / 97$ \\
\hline 7 & $\mathrm{NaOH}$ & 2.5 & 0.77 & 82 & 45 & 96 & $125 / 167$ \\
\hline 8 & $\mathrm{NaOH}$ & 2 & 0 & 82 & 45 & 11 & - \\
\hline 9 & $\mathrm{NaOH}$ & 2 & 0.24 & 82 & 45 & 27 & $112 / 149$ \\
\hline 10 & $\mathrm{NaOH}$ & 2 & 0.48 & 82 & 45 & 49 & $102 / 136$ \\
\hline 11 & $\mathrm{NaOH}$ & 2 & 0.96 & 82 & 45 & 96 & $100 / 133$ \\
\hline 12 & $\mathrm{NaOH}$ & 2 & 0.77 & 25 & 45 & 15 & $20 / 27$ \\
\hline 13 & $\mathrm{NaOH}$ & 2 & 0.77 & 50 & 45 & 37 & $48 / 64$ \\
\hline 14 & $\mathrm{NaOH}$ & 2 & 0.77 & 70 & 45 & 52 & $68 / 91$ \\
\hline 15 & $\mathrm{NaOH}$ & 2 & 0.77 & 82 & 0 & 0 & - \\
\hline 16 & $\mathrm{NaOH}$ & 2 & 0.77 & 82 & 10 & 29 & $38 / 224$ \\
\hline 17 & $\mathrm{NaOH}$ & 2 & 0.77 & 82 & 20 & 45 & $58 / 77$ \\
\hline 18 & $\mathrm{NaOH}$ & 2 & 0.77 & 82 & 30 & 59 & $77 / 154$ \\
\hline 19 & $\mathrm{NaOH}$ & 2 & 0.77 & 82 & 40 & 78 & $101 / 151$ \\
\hline 20 & $\mathrm{NaOH}$ & 2 & 0.77 & 82 & 60 & 96 & $125 / 125$ \\
\hline 21 & $\mathrm{NaOH}$ & 2 & 0.77 & 82 & 70 & 96 & $125 / 107$ \\
\hline 22 & $\mathrm{NaOH}$ & 2 & 0.77 & 82 & 80 & 97 & $126 / 95$ \\
\hline 23 & $\mathrm{NaOH}$ & 2 & 0.77 & 82 & 90 & 97 & $126 / 84$ \\
\hline
\end{tabular}

${ }^{a}$ All the reactions were performed with $1.0 \mathrm{mmol}(117.0 \mu \mathrm{L})$ of acetophenone. ${ }^{b} \mathrm{~A} 5 \mathrm{~mL}$ aliquot of $i$-PrOH was used in all the reactions. ${ }^{c} \mathrm{GC}$ yield. ${ }^{d}$ TON/TOF [TON $=$ the amount of product (mol) / the amount of active sites; TOF $=$ TON/time (h)]. 


\section{Table 2}

$\mathrm{RuO}_{2} / \mathrm{MWCNT}$-catalyzed transfer hydrogenation of aldehydes ${ }^{a}$.

\begin{tabular}{|c|c|c|c|c|c|c|c|}
\hline entry & substrate & product & $\begin{array}{l}\text { time } \\
(\min )\end{array}$ & $\begin{array}{c}\text { conv. }^{b} \\
(\%)\end{array}$ & $\begin{array}{l}\text { sel. }^{b} \\
(\%)\end{array}$ & $\begin{array}{c}\text { yield }^{b} \\
(\%)\end{array}$ & $\begin{array}{c}\text { TON/ } \\
\left(\mathrm{TOF} \mathrm{h}^{-1}\right)\end{array}$ \\
\hline 1 & & & 45 & 95 & 100 & 95 & $123 / 160$ \\
\hline 2 & & & 45 & 88 & 91 & 79 & $103 / 134$ \\
\hline 3 & & & 45 & 76 & 100 & 76 & $99 / 129$ \\
\hline & & & 45 & 63 & 88 & 51 & $66 / 86$ \\
\hline & & & 45 & 97 & 100 & 97 & $126 / 167$ \\
\hline 6 & & & 45 & 79 & 100 & 79 & $103 / 134$ \\
\hline 7 & & & 45 & 69 & 82 & 51 & $66 / 86$ \\
\hline & & & 120 & 74 & 80 & 54 & $70 / 35$ \\
\hline 9 & & & 120 & 89 & 100 & 89 & $116 / 58$ \\
\hline 10 & & & 45 & 80 & 95 & 75 & $97 / 126$ \\
\hline
\end{tabular}


${ }^{a}$ Reaction conditions: Substrate $(1 \mathrm{mmol}), \mathrm{RuO}_{2} / \mathrm{MWCNT}$ (0.77 mol\%), $\mathrm{NaOH}$ (2 mmol), $i$-PrOH $(5 \mathrm{~mL}), 82^{\circ} \mathrm{C} .{ }^{b}$ Determined by GC analysis.

Table 3

$\mathrm{RuO}_{2} / \mathrm{MWCNT}$-catalyzed transfer hydrogenation of ketones ${ }^{a}$.

\begin{tabular}{|c|c|c|c|c|c|c|c|}
\hline entry & substrate & product & $\begin{array}{l}\text { time } \\
(\mathrm{min})\end{array}$ & $\begin{array}{c}\text { conv. }^{b} \\
(\%)\end{array}$ & $\begin{array}{l}\text { sel. }^{b} \\
(\%)\end{array}$ & $\begin{array}{c}\text { yield }^{b} \\
(\%)\end{array}$ & $\begin{array}{c}\text { TON/ } \\
\left(\mathrm{TOF} \mathrm{h}^{-1}\right)\end{array}$ \\
\hline 1 & & & 45 & 96 & 100 & 96 & $125 / 167$ \\
\hline & & & 45 & 95 & 97 & 92 & $120 / 160$ \\
\hline 3 & & & 45 & 88 & 100 & 88 & $114 / 152$ \\
\hline 4 & & & 45 & 81 & 86 & 67 & $87 / 116$ \\
\hline 5 & & & 50 & 95 & 100 & 95 & $123 / 148$ \\
\hline 6 & & & 45 & 91 & 100 & 91 & $118 / 157$ \\
\hline 7 & & & 45 & 86 & 87 & 73 & $95 / 127$ \\
\hline 8 & & & 30 & 97 & 98 & 95 & $123 / 246$ \\
\hline
\end{tabular}




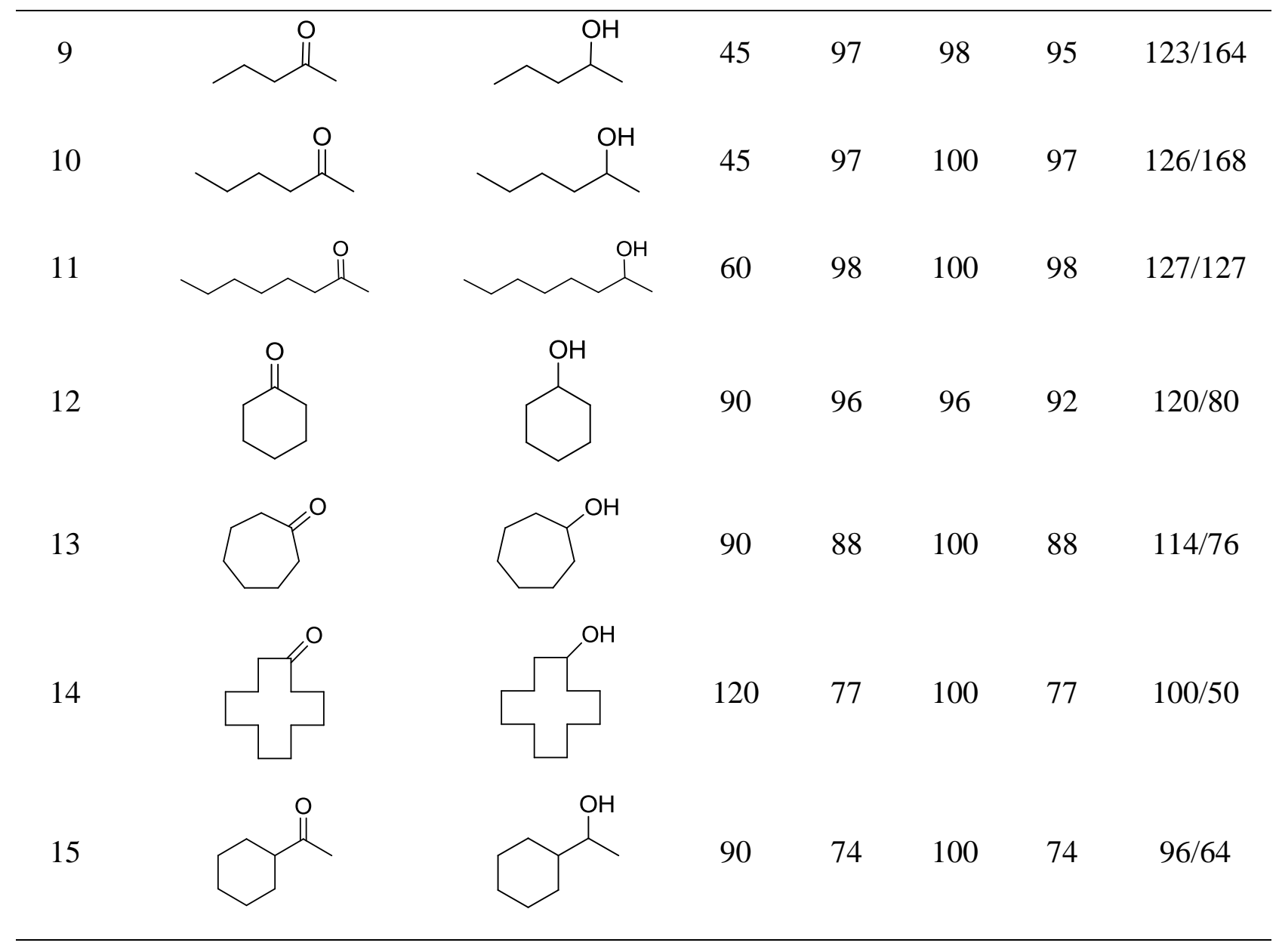

${ }^{a}$ Reaction conditions: Substrate (1 mmol), $\mathrm{RuO}_{2} / \mathrm{MWCNT}$ (0.77 mol\%), $\mathrm{NaOH}$ (2 mmol), $i$-PrOH $(5 \mathrm{~mL}), 82^{\circ} \mathrm{C} .{ }^{b}$ Determined by GC analysis. 


\section{Table 4}

$\mathrm{RuO}_{2} / \mathrm{MWCNT}$-catalyzed transfer hydrogenation of heterocyclic carbonyl compounds ${ }^{a}$.

\begin{tabular}{|c|c|c|c|c|c|c|c|}
\hline entry & substrate & product & $\begin{array}{l}\text { time } \\
(\mathrm{min})\end{array}$ & $\begin{array}{c}\text { conv. }^{b} \\
(\%)\end{array}$ & $\begin{array}{l}\text { sel. }^{b} \\
(\%)\end{array}$ & $\begin{array}{c}\text { yield }^{b} \\
(\%)\end{array}$ & $\begin{array}{c}\text { TON/ } \\
\left(\mathrm{TOF} \mathrm{h}^{-1}\right)\end{array}$ \\
\hline 1 & & & 90 & 97 & 100 & 97 & $126 / 84$ \\
\hline 2 & & & 90 & 78 & 96 & 74 & $96 / 64$ \\
\hline 3 & & & 120 & 95 & 93 & 88 & $114 / 57$ \\
\hline 4 & & & 100 & 96 & 100 & 96 & $125 / 75$ \\
\hline 5 & & & 100 & 77 & 100 & 77 & $100 / 60$ \\
\hline
\end{tabular}

${ }^{a}$ Reaction conditions: Substrate ( $\left.1 \mathrm{mmol}\right), \mathrm{RuO}_{2} / \mathrm{MWCNT}$ (0.77 mol\%), $\mathrm{NaOH}$ (2 mmol), $i$-PrOH $(5 \mathrm{~mL}), 82^{\circ} \mathrm{C} .{ }^{b}$ Determined by GC analysis. 


\section{Table 5}

Chemoselective transfer hydrogenation of carbonyl compounds catalyzed by $\mathrm{RuO}_{2} / \mathrm{MWCNT}^{a}$.

entry substrate

${ }^{a}$ Reaction conditions: Substrate (1 mmol), $\mathrm{RuO}_{2} / \mathrm{MWCNT}$ (0.77 mol\%), $\mathrm{NaOH}$ (2 mmol), $i$-PrOH $(5 \mathrm{~mL}), 82^{\circ} \mathrm{C} .{ }^{b}$ Determined by GC analysis. 


\section{Table 6}

Catalytic activity of $b-\mathrm{RuO}_{2} / \mathrm{MWCNT}$ in the transfer hydrogenation of carbonyl compounds ${ }^{a}$.

entry substrate

${ }^{a}$ Reaction conditions: Substrate ( $\left.1 \mathrm{mmol}\right), \mathrm{RuO}_{2} / \mathrm{MWCNT}(0.78 \mathrm{~mol} \%), \mathrm{NaOH}(2 \mathrm{mmol})$, $i$-PrOH $(5 \mathrm{~mL}), 82^{\circ} \mathrm{C} .{ }^{b}$ Determined by $\mathrm{GC}$ analysis. 


\section{Table 7}

Oxidation of alcohols catalyzed by $r-\mathrm{RuO}_{2} / \mathrm{MWCNT}^{a}$.

Entry Substrate

${ }^{a}$ Reaction conditions: Substrate $(1 \mathrm{mmol}), r-\mathrm{RuO}_{2} / \mathrm{MWCNT}(0.68 \mathrm{~mol} \%)$, toluene $(3 \mathrm{~mL})$, $110^{\circ} \mathrm{C} .{ }^{b}$ Determined by GC analysis. 


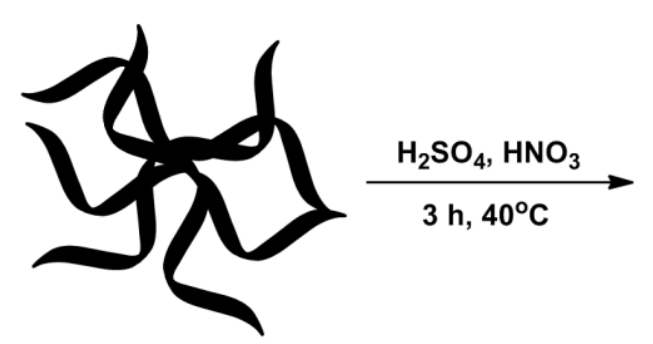

MWCNTs

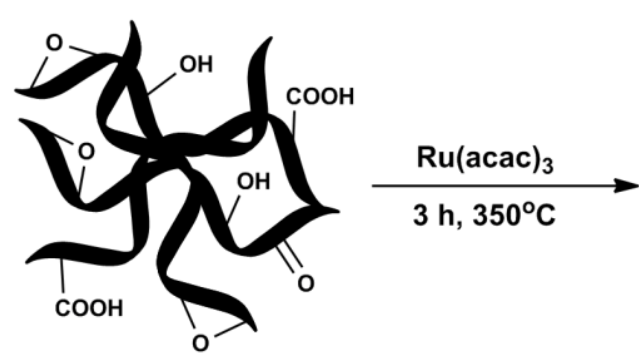

$f$-MWCNTs

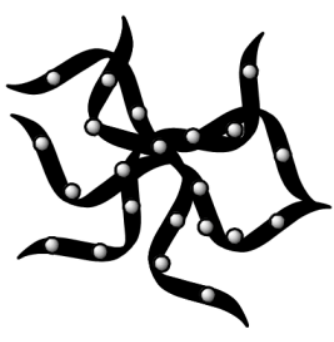

$\mathrm{RuO}_{2} / \mathrm{MWCNT}$

Fig. 1. Schematic illustration for the preparation of $\mathrm{RuO}_{2} / \mathrm{MWCNT}$.

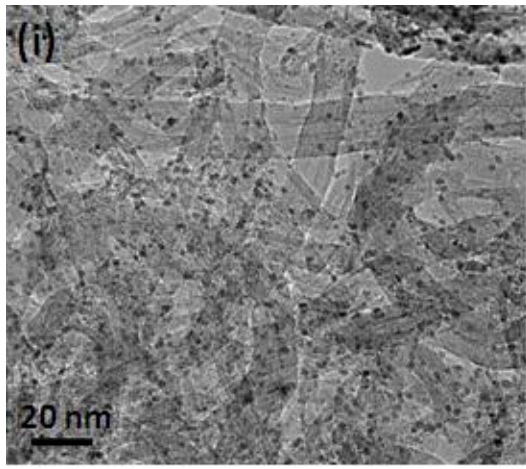

(iv) $10 \mathrm{~nm}$
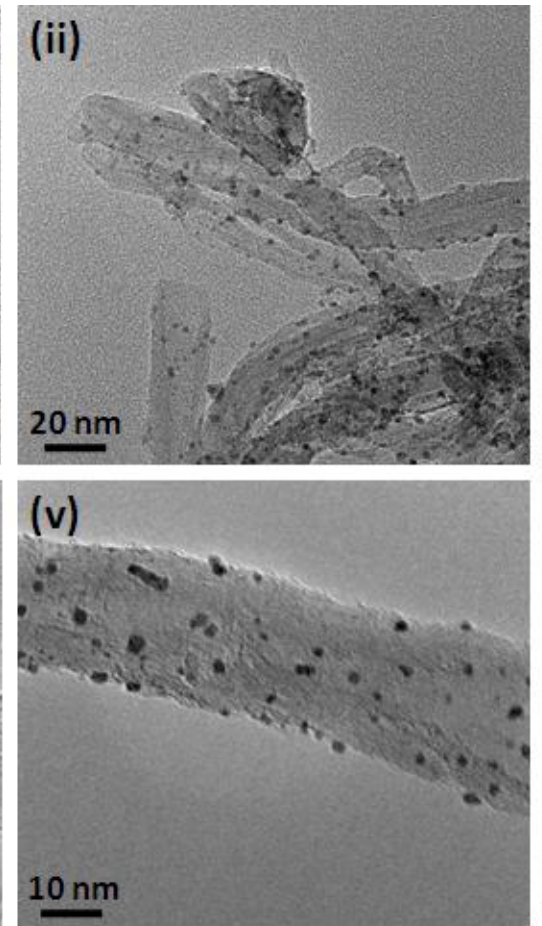
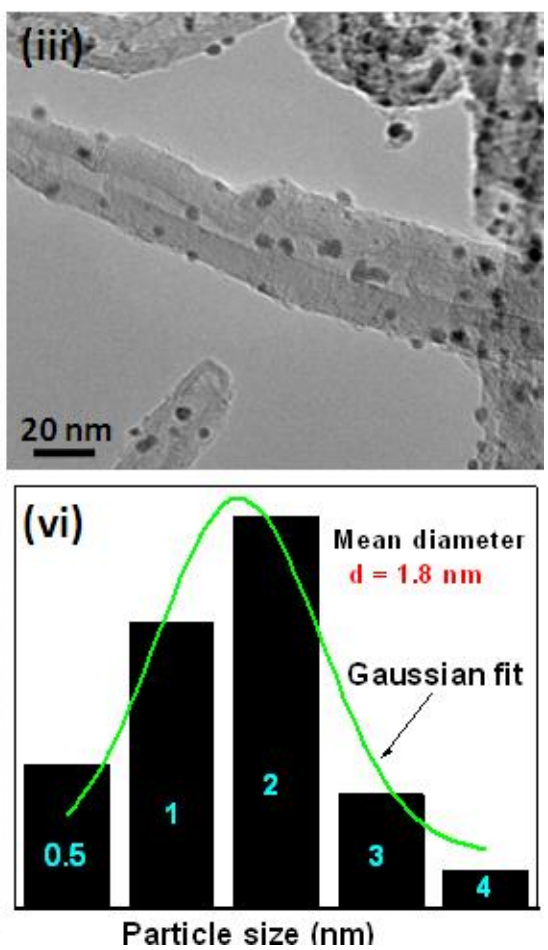

Fig. 2. (i, ii, iii, iv and v) TEM images of $\mathrm{RuO}_{2} / \mathrm{MWCNT}$ and (vi) the particle size distribution of $\mathrm{RuO}_{2} \mathrm{NPs}$. 

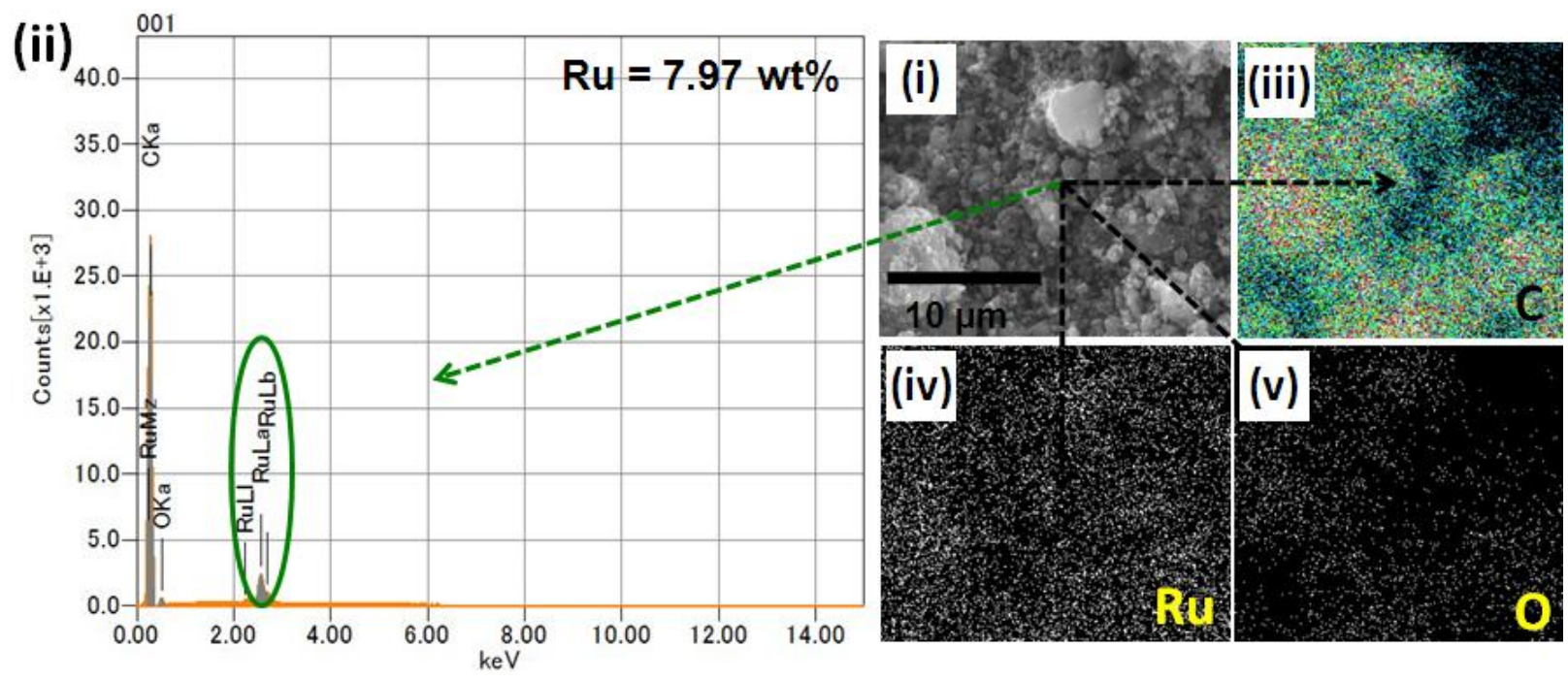

Fig. 3. (i) SEM image and (ii) EDS spectrum of $\mathrm{RuO}_{2} / \mathrm{MWCNT}$, and corresponding EDS mapping of (iii) $\mathrm{C}$, (iv) $\mathrm{Ru}$ and (v) $\mathrm{O}$.
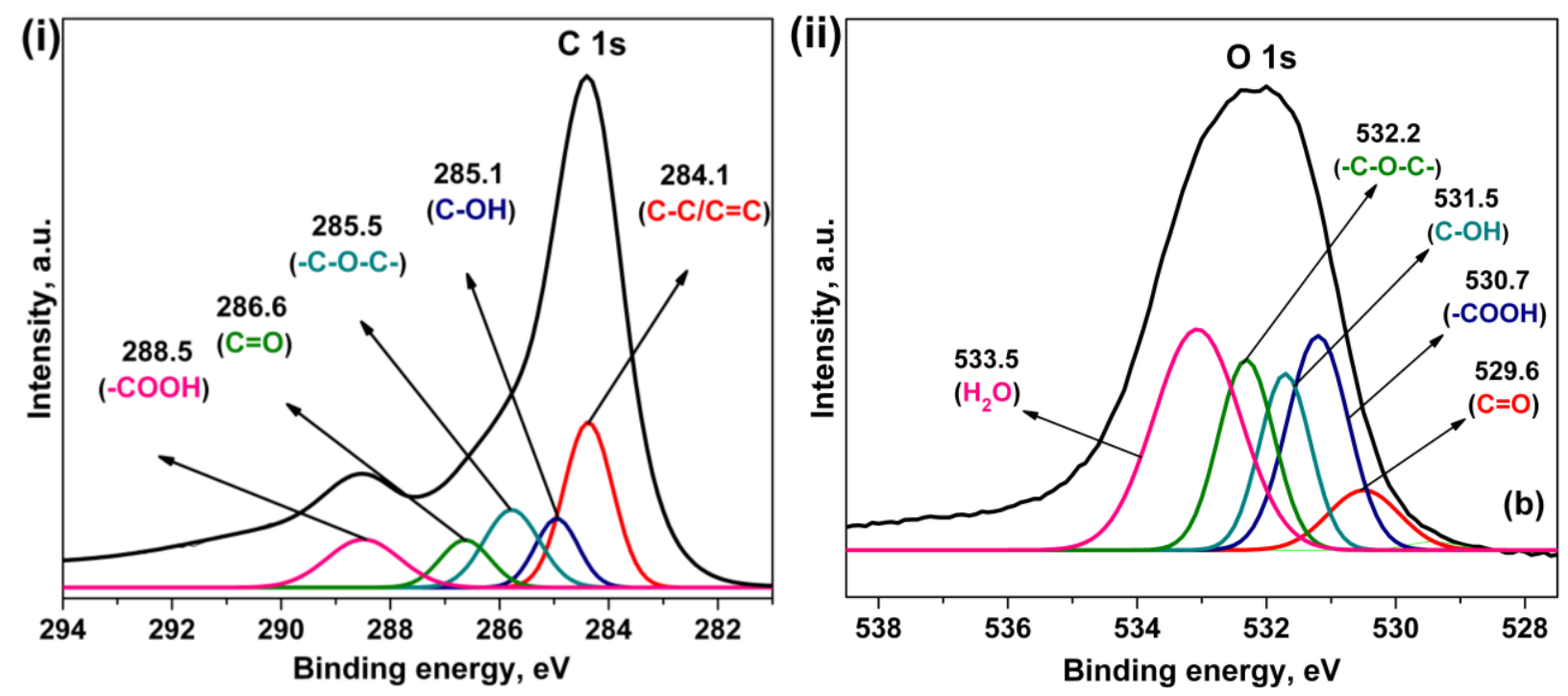

Fig. 4. XPS spectra of $f$-MWCNTs; magnified (i) $\mathrm{C} 1 \mathrm{~s}$ and (ii) $\mathrm{O} 1 \mathrm{~s}$ peaks. 

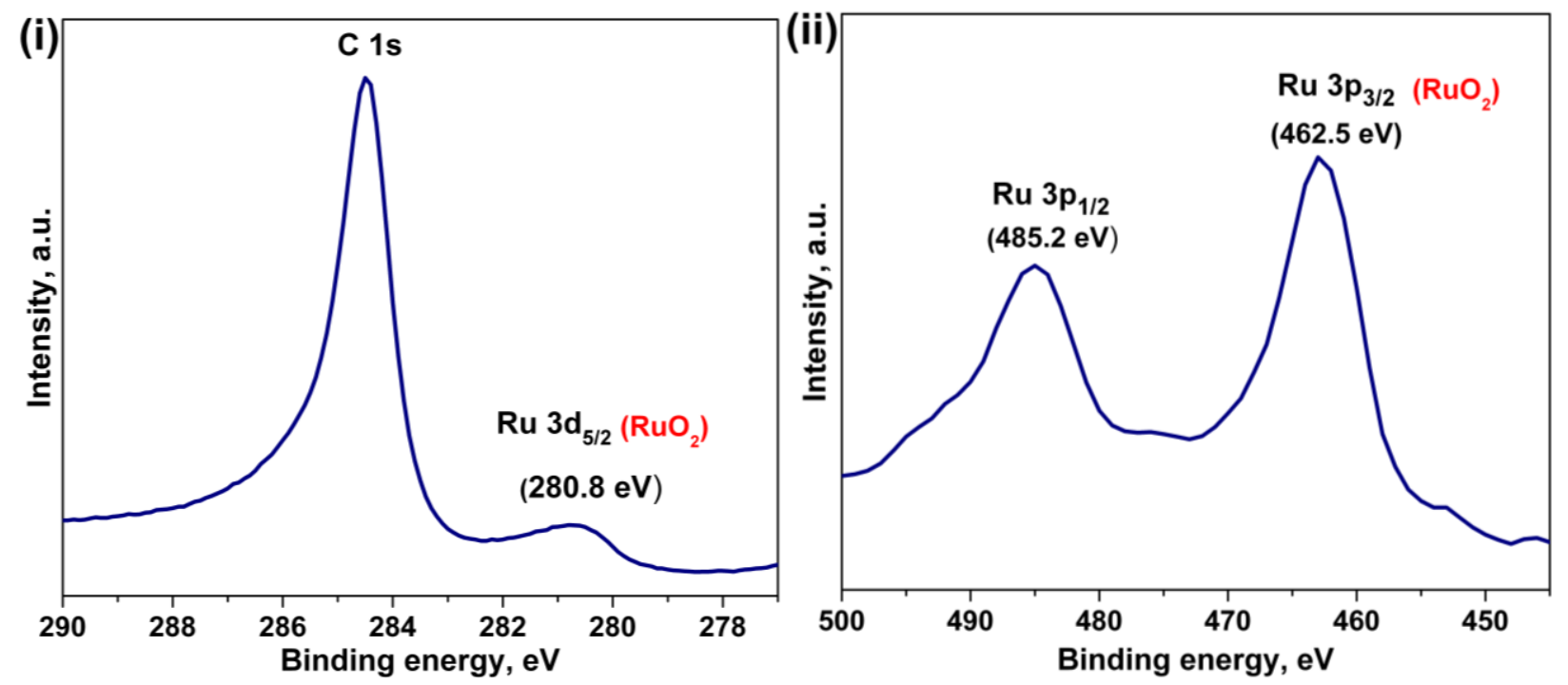

Fig. 5. XPS spectra of $\mathrm{RuO}_{2} / \mathrm{MWCNT}$; magnified (i) $\mathrm{C} 1$ s and (ii) $\mathrm{Ru} 3 p$ peaks.
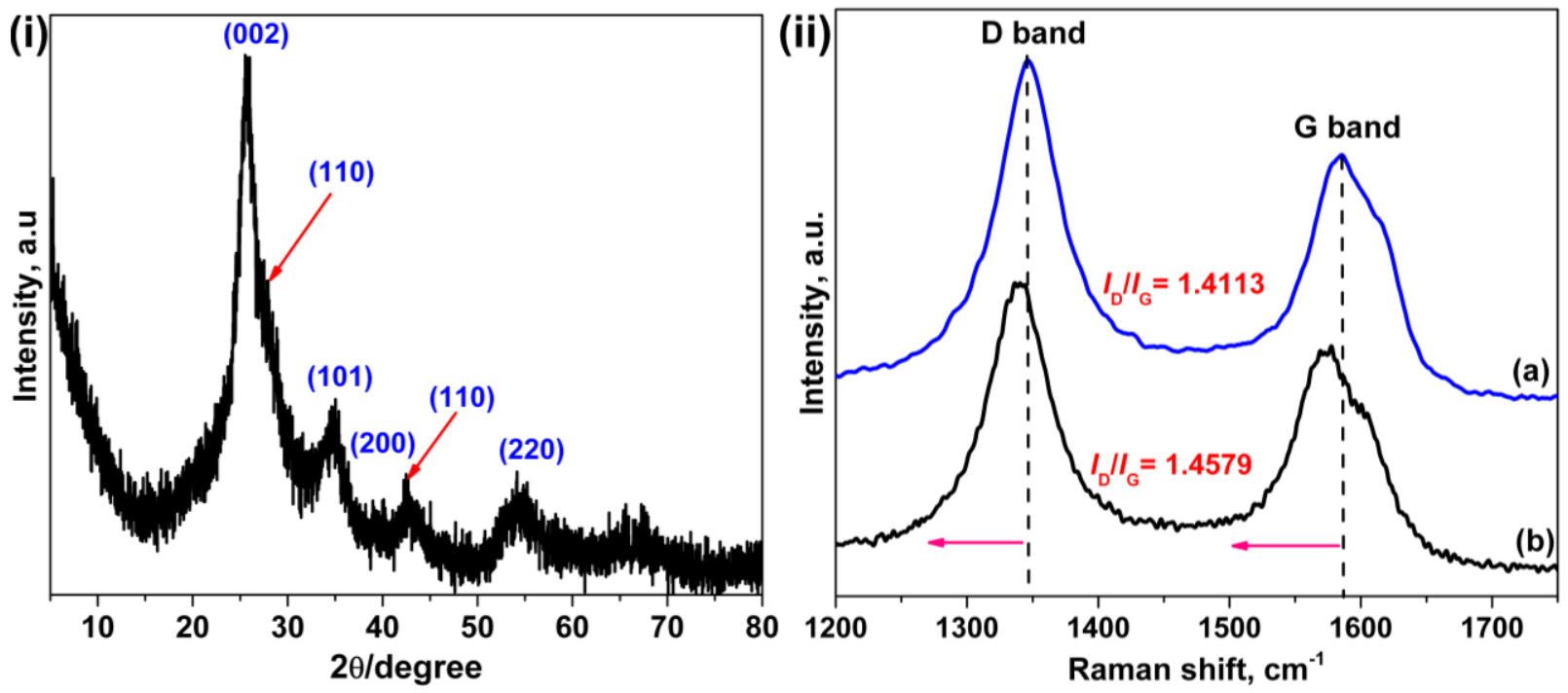

Fig. 6. (i) $\mathrm{XRD}$ pattern of $\mathrm{RuO}_{2} / \mathrm{MWCNT}$ and (ii) Raman spectra of $f$-MWCNTs (a) and $\mathrm{RuO}_{2} / \mathrm{MWCNT}$ (b). 

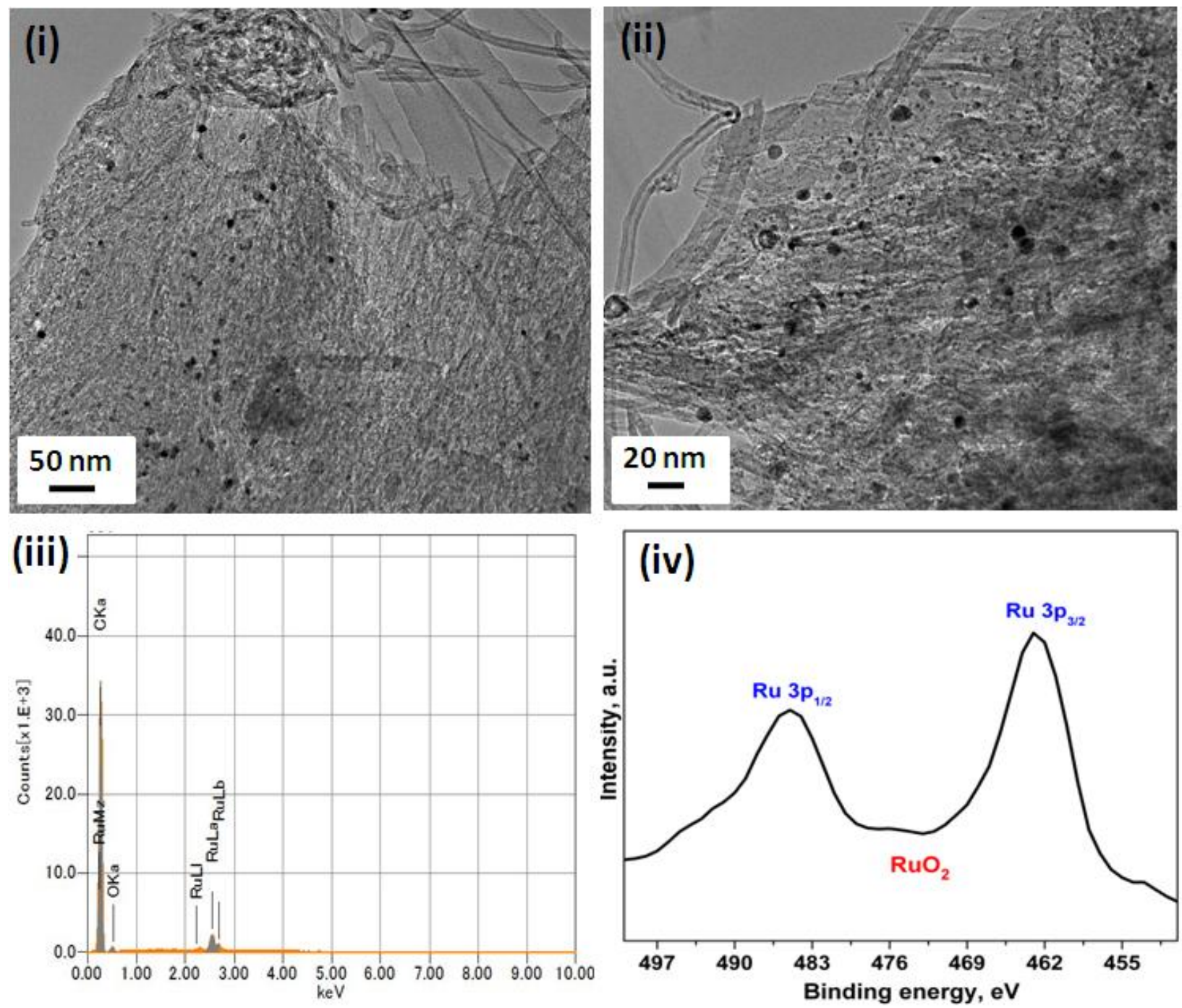

Fig. 7. (i and ii) TEM images of $\mathrm{RuO}_{2} / \mathrm{MWCNT}$, (iii) EDS spectrum of $\mathrm{RuO}_{2} / \mathrm{MWCNT}$ and (iv) $\mathrm{Ru} 3 \mathrm{p}$ peaks of $\mathrm{RuO}_{2} / \mathrm{MWCNT}$. 

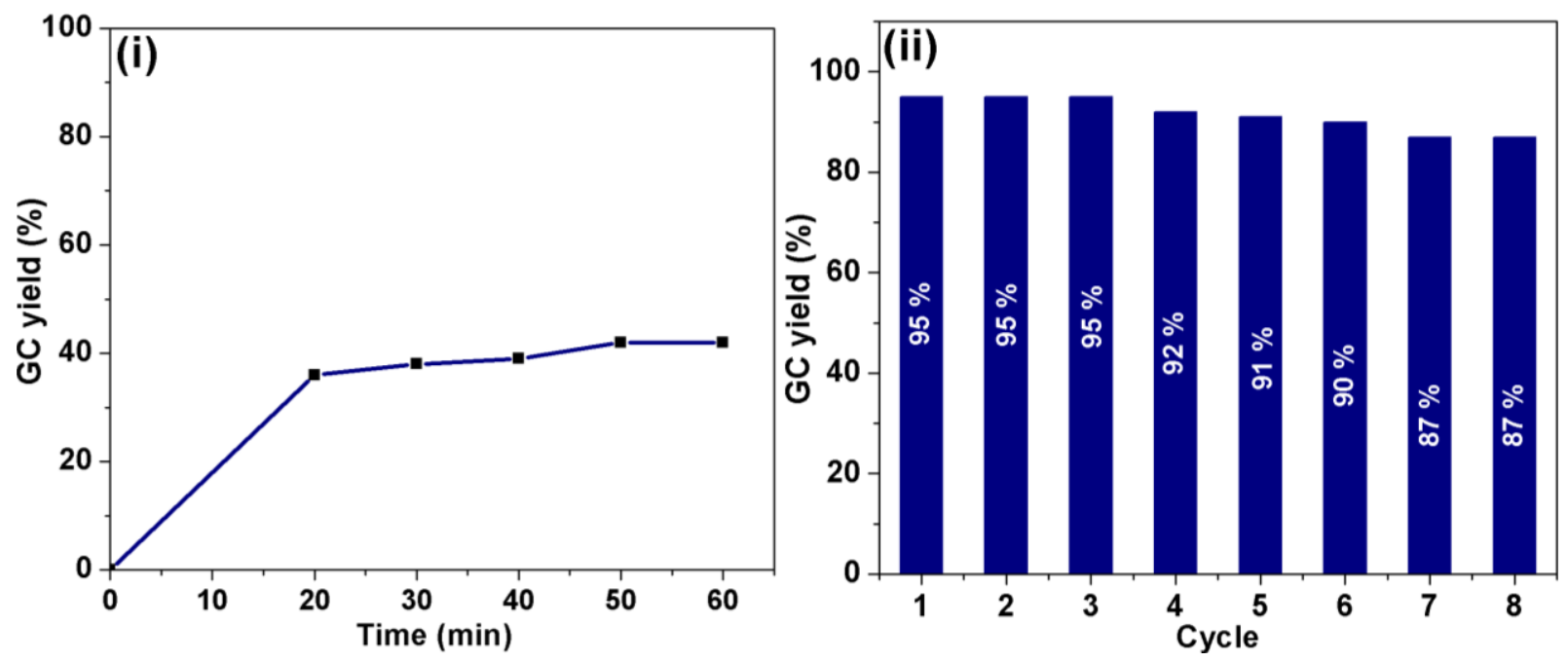

Fig. 8. (i) Heterogeneity and (ii) recyclability of $\mathrm{RuO}_{2} / \mathrm{MWCNT}$ for transfer hydrogenation of acetophenone. [Reaction conditions: $117 \mu \mathrm{L}$ of acetophenone $(1 \mathrm{mmol}), 80 \mathrm{mg}$ of $\mathrm{NaOH}(1$ mmol), $5 \mathrm{mg}$ of $\mathrm{RuO}_{2} / \mathrm{MWCNT}(0.77 \mathrm{~mol} \%)$ and $5 \mathrm{~mL}$ of $i-\mathrm{PrOH}$ at $82^{\circ} \mathrm{C}$ for $\left.45 \mathrm{~min}\right]$.
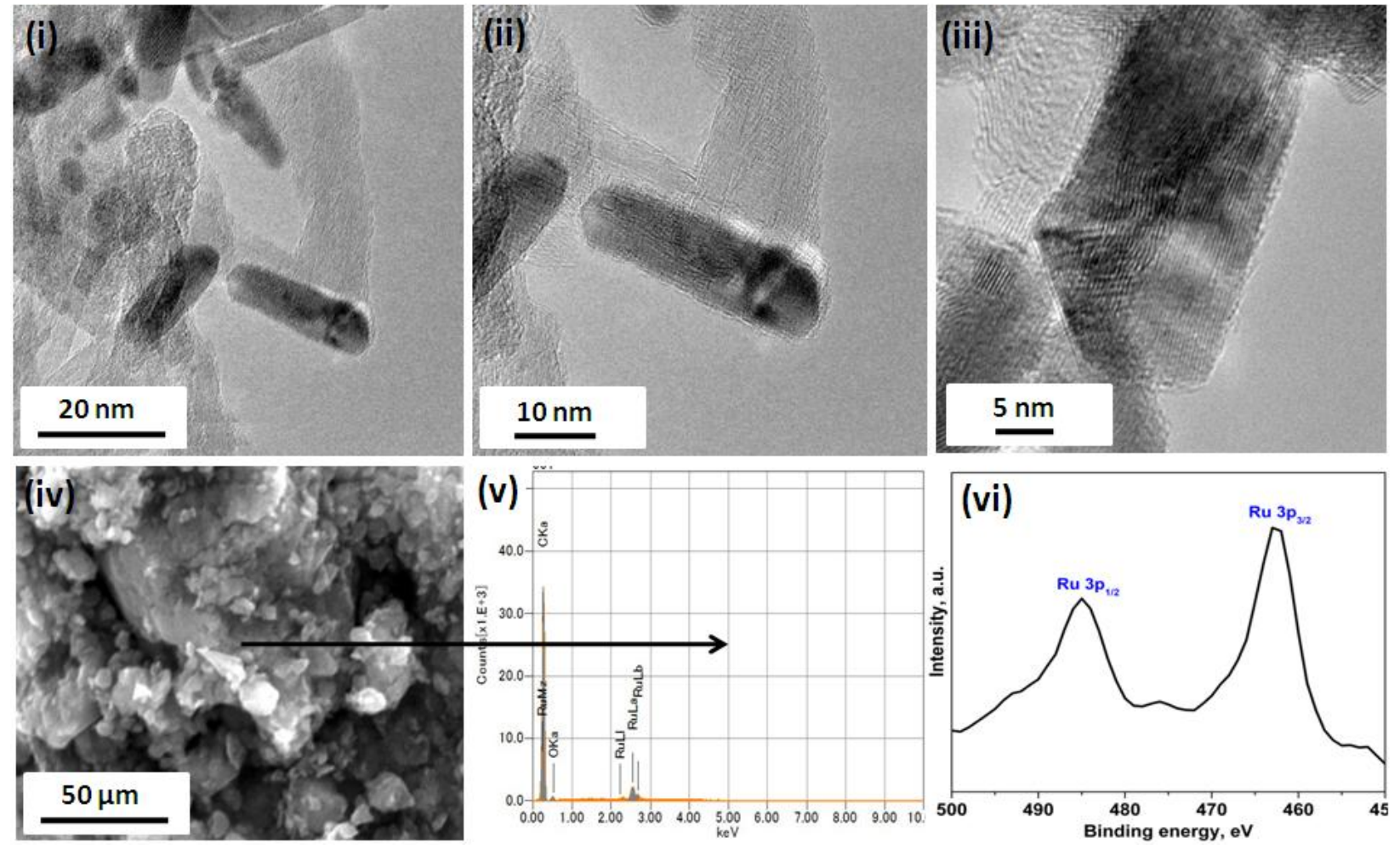

Fig. 9. (i, ii and iii) TEM images, (iv) SEM image, (v) EDS spctrum and (vi) Ru 3p peaks of $r$ $\mathrm{RuO}_{2} / \mathrm{MWCNT}$. 
Supplementary Material

Click here to download Supplementary Material: Supplementary Material.R2.doc

C

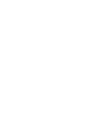

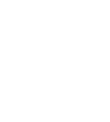

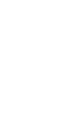

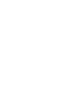

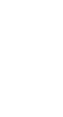
tary Material: Supplementary Material.R2.doc pplementary Material: Supplementary Material.R2.doc pplementary Material: Supplementary Material.R.doc (1) pplementary Material: Supplementary Material.R2.doc (1) (1) (1) (1) (1) (1) (1) (1) (1) (1) (1) (1) (1) (1) (1) (1) (1) (1) (1) (1) (1) (1) (1) 更 (1) 